\title{
The fructan syndrome: Evolutionary aspects and common themes among plants and microbes
}

\author{
Maxime Versluys $^{1 \dagger} \mid$ Onur Kirtel $^{2 \dagger} \mid$ Ebru Toksoy Öner ${ }^{2} \mid$ Wim Van den Ende ${ }^{1}$ (D)
}

\author{
${ }^{1}$ Laboratory of Molecular Plant Biology, KU \\ Leuven, Leuven, Belgium \\ ${ }^{2}$ Industrial Biotechnology and Systems \\ Biology Research Group, Bioengineering \\ Department, Marmara University, Istanbul \\ 34722, Turkey

\section{Correspondence} \\ W. Van den Ende, Laboratory of Molecular \\ Plant Biology, KU Leuven, Leuven, Belgium. \\ Email: wim.vandenende@bio.kuleuven.be \\ Funding information \\ TUBITAK, Grant/Award Number: project \\ 1150495; Marmara University Research \\ Foundation, Grant/Award Number: project \\ FEN-D-100616-0301; FWO Vlaanderen, \\ Grant/Award Number: 1125318 N
}

\begin{abstract}
Fructans are multifunctional fructose-based water soluble carbohydrates found in all biological kingdoms but not in animals. Most research has focused on plant and microbial fructans and has received a growing interest because of their practical applications. Nevertheless, the origin of fructan production, the so-called "fructan syndrome," is still unknown. Why fructans only occur in a limited number of plant and microbial species remains unclear. In this review, we provide an overview of plant and microbial fructan research with a focus on fructans as an adaptation to the environment and their role in (a)biotic stress tolerance. The taxonomical and biogeographical distribution of fructans in both kingdoms is discussed and linked (where possible) to environmental factors. Overall, the fructan syndrome may be related to water scarcity and differences in physicochemical properties, for instance, water retaining characteristics, at least partially explain why different fructan types with different branching levels are found in different species. Although a close correlation between environmental stresses and fructan production is quite clear in plants, this link seems to be missing in microbes. We hypothesize that this can be at least partially explained by differential evolutionary timeframes for plants and microbes, combined with potential redundancy effects.
\end{abstract}

\section{1 | INTRODUCTION}

The best known nonstructural carbohydrates in biological systems are glucose-based polysaccharides, such as starch (plants) and glycogen (animals). Another important type of nonstructural carbohydrates found in almost all biological kingdoms, with the exception of animals, is fructose-based oligo and polysaccharides, known as fructans. In the broadest possible sense, fructans are defined as any compound where one or more fructosyl-fructose linkages ( $\beta-2,1$ and/or $\beta-2,6$ linkages) constitute the majority of the linkages. From that point of view, levanbiose (Fru 2,6 Fru) and inulobiose (Fru 2,1 Fru) are to be considered as the smallest fructan species. Thus, one glucose moiety can be present or absent in fructan structures (Lewis, 1993).

Fructans occur in microbes and plants and to a lesser extent in some fungi and certain algal species of the Dasycladales and Cladophorales. The ability to synthesize and store fructans, the so-called fructan syndrome, is restricted to certain taxonomical groups, especially in plants where the use of fructans is mainly confined to a limited number of orders. In microbes, they appear in certain families of both gram-positive and gram-negative bacteria. From an

\footnotetext{
${ }^{\dagger}$ These authors contributed equally to this work.
}

evolutionary perspective, it is still unclear why the ability to produce these oligo and polysaccharides is limited to certain taxa (Hendry, 1993; Hendry \& Wallace, 1993).

Fructans are historically considered as storage carbohydrates, but other possible functions have been proposed both in microbes and plants, mainly their potential involvement in (a)biotic stress resistance. Although $\beta-(2,1)$ and $\beta-(2,6)$ linkages occur both in microbial and plant-derived fructans, microbial fructans typically show a much higher degree of polymerization (DP) as compared to plant fructans (Toksoy Öner, Hernández, \& Combie, 2016; Van den Ende, 2013). The fructan syndrome has often been linked to "stressful environments". However, the definition of a stressful environment in itself may greatly depend on human perception. For example, hot springs may be perceived as an extremely stressful environment from human point of view, whereas these are just "standard" environments for extremophiles. Perhaps, the question can be reformulated for microbes: Did fructans, from an evolutionary perspective, assist microbes to adapt to extreme conditions, and are fructans still essential nowadays to persist under such conditions? For higher plants, it is more a question whether stress-mediated fructan induction during the life cycle of a plant indeed helps to counteract certain stresses. To our knowledge, such 
views have never been integrated crossing the borders of plants and microbes.

In the following paragraphs, we will provide a comprehensive overview of fructan research in microbe and plant domains with a strong focus on their potential role in stress resistance and/or adaptation to extreme environments, based on recent examples from the literature. In Section 2, we will elaborate on the parallels in fructan structure and metabolizing enzymes among plant and microbial lineages. Then, the differences in fructan function in light of adaptation to environmental stresses between both kingdoms will be discussed. As plants cannot tolerate the highly extreme conditions in which extremophilic microbes survive and thrive, it is clear that "stressful conditions" cannot be directly compared for both groups. Nevertheless, we will try to link the ability to produce fructans with the survival of microbes and plants in stressful and extreme environmental conditions, or provide explanations why such link is sometimes unclear or nonexistent.

\section{I FRUCTANS AND THE GH-J CLAN ENZYMES}

\section{1 | The fructan syndrome}

Fructans produced by microbes are mostly levan-type fructans with $\beta-2,6$ linkages between fructofuranosyl units on the polymer backbone and varying degrees of branching on $\beta-2,1$ positions. Microbial levans are produced by a wide range of different gram-negative and gram-positive bacteria (see Table 1 below). On the other hand, microbial inulins (a backbone of $\beta-2,1$ linkages between fructofuranosyl units with $\beta-2,6$ branches) are only produced by a limited number of gram-positive bacteria belonging to genera of Lactobacillus, Leuconostoc, Streptococcus, and Weissella (Anwar, Kralj, van der Maarel, \& Dijkhuizen, 2008; Malang, Maina, Schwab, Tenkanen, \& Lacroix, 2015; Peña-Cardeña, Rodríguez-Alegría, Olvera, \& Munguía, 2015; Rosell \& Birkhed, 1974), and the literature is very scarce as compared to levan. In fact, levan production by different microbes has been studied well for over a few decades, and it was revealed that levan shows significantly different physicochemical properties such as branching degree, molecular weight, intrinsic viscosity, and functional properties such as adhesive strength and immunogenic activity, depending on the microbial strains used and various fermentation conditions. Considering these, a lot of effort has been put to obtain levans with different properties because this polymer exhibits exceptional potential in chemical, food, medical, pharmaceutical, and cosmetic areas (Han, 1990; Toksoy Öner et al., 2016).

Microbial fructans are characterized by much higher DP as compared to plant fructans, up to more than 20.000 fructosyl units (Han, Xu, Gao, Liu, \& Wu, 2016; Kazak Sarilmiser, Ates, Ozdemir, Arga, \& Toksoy, 2015; Ortiz-Soto, Rivera, Rudiño-Piñera, Olvera, \& López-Munguía, 2008), and mainly consisting of levan- or inulin-type polymers with variable branching and sometimes accompanied by various lower DP fructooligosaccharides (FOS), albeit mostly present at much lower concentrations (Figure 1a). In microbes, levan and inulin are synthesized by extracellular fructosyltransferases (FTs) named levansucrase (EC 2.4.1.10) and inulosucrase (EC 2.4.1.9), respectively. Both belong to the GH68 enzyme family.

Levansucrase typically uses sucrose as preferential donor substrate, by hydrolysing it and transferring the resulting fructose moiety to an acceptor sucrose molecule, thus creating a 6-kestotriose molecule. Repetitive addition of fructose moieties to this growing

TABLE 1 Common bacterial and fungal exopolysaccharides in nature

\begin{tabular}{|c|c|c|c|}
\hline Exopolysaccharide & Chemical structure & Producer genera & References \\
\hline Alginate & $\begin{array}{l}\beta \text {-D-mannuronic acid and } a \text { - }- \text {-guluronic acid residues in varying } \\
\text { ratios, linked by } 1,4 \text { glycosidic bonds }\end{array}$ & Pseudomonas, Azotobacter & $\begin{array}{l}\text { Hay, Rehman, } \\
\text { Moradali, Wang, and } \\
\text { Rehm (2013) }\end{array}$ \\
\hline Curdlan & Linear $\beta$-1,3 D-glucose backbone & Agrobacterium, Alcaligenes & $\begin{array}{l}\text { Rafigh, Yazdi, } \\
\text { Vossoughi, } \\
\text { Safekordi, and } \\
\text { Ardjmand (2014) }\end{array}$ \\
\hline Gellan & $\begin{array}{l}\text { Repeating tetrasaccharide backbone of two D-glucose, one } \\
\text { L-rhamnose and one D-glucuronic acid, with O-acetylation } \\
\text { and L-glycerate on ca. } 50 \% \text { of D-glucose residues }\end{array}$ & Sphingomonas & Pollock (1993) \\
\hline a-Glucans & $\begin{array}{l}\text { Homopolymers of D-glucose with various a-glycosidic linkages } \\
\text { on their backbones and branches }\end{array}$ & $\begin{array}{l}\text { Lactobacillus, Leuconostoc, Streptococcus, } \\
\text { Weisella }\end{array}$ & Leemhuis et al. (2013) \\
\hline Inulin & $\begin{array}{l}\beta-2,1 \text { linked D-fructose backbone with or without } \beta-2,6 \text { linked } \\
\text { D-fructose branches }\end{array}$ & $\begin{array}{l}\text { Lactobacillus, Leuconostoc, Streptococcus, } \\
\text { Weissella }\end{array}$ & Anwar et al. (2008) \\
\hline Levan & $\begin{array}{l}\beta-2,6 \text { linked D-fructose backbone with or without } \beta-2,1 \text { linked } \\
\text { D-fructose branches }\end{array}$ & $\begin{array}{l}\text { Bacillus, Erwinia, Gluconacetobacter, } \\
\text { Halomonas, Pseudomonas, } \\
\text { Streptococcus salivarius, Zymomonas }\end{array}$ & $\begin{array}{l}\text { Toksoy Öner et al. } \\
\text { (2016) }\end{array}$ \\
\hline Pullulan & $\begin{array}{l}\text { Maltotriose and maltotetraose repeating units linked by } a-1,6 \\
\text { and } a-1,4 \text { linkages }\end{array}$ & Aureobasidium, Tremella, Cytaria & $\begin{array}{l}\text { Vasiliu, Racovita, } \\
\text { Lungan, Desbrieres, } \\
\text { and Popa (2016) }\end{array}$ \\
\hline Scleroglucan & $\begin{array}{l}\beta-1,3 \text { linked D-glucose backbone with } \beta-1,6 \text { linked D-glucose } \\
\text { branches }\end{array}$ & $\begin{array}{l}\text { Botrytis, Epicoccum, Sclerotium, } \\
\text { Schizophyllum }\end{array}$ & $\begin{array}{l}\text { Schmid, Meyer, and } \\
\text { Sieber (2011) }\end{array}$ \\
\hline Xanthan & $\begin{array}{l}\beta-1,4 \text { linked D-glucose backbone with branches of two mannose } \\
\text { residues and a D-glucuronic acid residue between. D-mannose } \\
\text { residues are acetylated and pyruvated to different degrees }\end{array}$ & Xanthomonas & $\begin{array}{l}\text { Habibi and Khosravi- } \\
\text { Darani (2017) }\end{array}$ \\
\hline
\end{tabular}




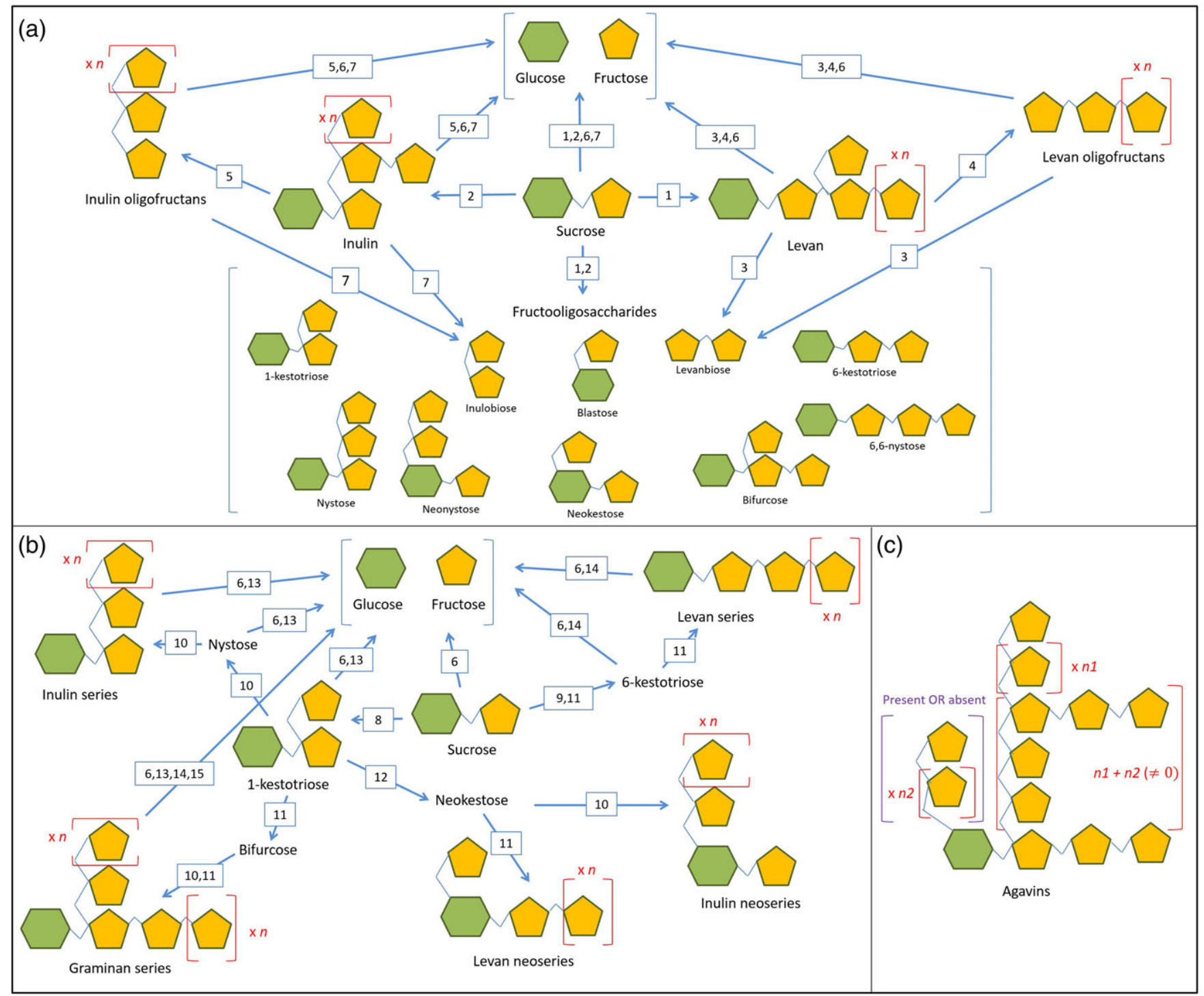

FIGURE 1 Microbial and plant fructan metabolism. (a) Fructan metabolism in microbes starting from the disaccharide sucrose. Depending on the linkage type, inulins ( $\beta-2,1$ linkage on the backbone, $\beta-2,6$ branching points) or levans ( $\beta-2,6$ linkage on the backbone, $\beta-2,1$ branching points) are produced by inulosucrase and levansucrase, respectively. These two enzymes may also produce different FOS instead of/along with inulin and levan, mostly depending on initial sucrose concentration and temperature of the environment. Additionally, levansucrase can produce blastose and levanbiose using glucose and fructose as acceptors, respectively. Levans and inulins can also be cleaved by levanases and inulinases, respectively, resulting in the release of different levan- or inulin-oligosaccharides, levanbiose, inulobiose, or glucose and fructose, depending on the exo- or endoactivity of these enzymes. Product and substrate specifications were determined using BRENDA enzyme database (http://www.brenda-enzymes.org). (b) In plants, all fructan synthesis starts from the disaccharide sucrose. Different fructosyltransferases conjugate fructose moieties to the substrate. Dependent on the linkage type, different series of fructans are recognized: $\beta-2,1$ linkages for inulin series, $\beta-2,6$ linkages for levan series, and both $\beta-2,1$ and $\beta-2,6$ linkages for graminan series. Neoseries of fructans are characterized by an internal a-glucose moiety (adapted from Di Bartolomeo \& Van den Ende, 2015). (c) A possible structure for the Agavins, fructans found in plants of the Agavaceae family, is shown (adapted from Mancilla-Margalli \& López, 2006). Numbers represent the following enzymes: 1 levansucrase (EC 2.4.1.10), 2 inulosucrase (EC 2.4.1.9), 3 exolevanase (EC 3.2.1.64), 4 endolevanase (EC 3.2.1.65), 5 endoinulinase (EC 3.2.1.7), 6 invertase/ $\beta$-fructofuranosidase (EC 3.2.1.26), 7 exoinulinase (EC 3.2.1.80), 8 sucrose:sucrose

1-fructosyltransferase (EC 2.4.1.99), 9 sucrose:sucrose 6-fructosyltransferase (EC 2.4.1.-), 10 fructan:fructan 1-fructosyltransferase (EC 2.4.1.100), 11 sucrose:fructan 6-fructosyltransferase (EC 2.4.1.10), 12 fructan:fructan 6G-fructosyltransferase (EC 2.4.1.243), 13 1-fructan exohydrolase (EC 3.2.1.153), 14 6-fructan exohydrolase (EC 3.2.1.154), and 15 6\&1-fructan exohydrolase (EC 3.2.1.-). FOS = fructooligosaccharides

6-kestotriose molecule creates a levan chain (Santos-Moriano et al., 2015). From a certain DP, the growing oligosaccharide chain remains bound to the enzyme, leading to an even more rapid elongation into the typical high DP levan polymer which also remains bound to levansucrase (Banguela et al., 2012; Toksoy Öner et al., 2016). Moreover, the enzyme can be induced to produce structurally various FOS instead of/along with high DP levan, by manipulating the reaction variables such as temperature and ionic strength. It is also possible to shift the reaction specificities of levansucrases by changing amino acid residues near the active site of the enzyme. For instance, Ortiz-Soto et al. (2017) modified Bacillus megaterium levansucrase to shift its dominant activity from sucrose hydrolysis to transfructosylation. Modification of two water-binding tyrosine residues and two serine residues with library variants resulted in increased hydrophobicity 
and a $50-200 \%$ increase in transfructosylation. Levansucrase can also transfer the fructose moiety to various other acceptors, such as the disaccharides maltose or lactose, creating trisaccharides erlose and lactosucrose, respectively. Unique biological activities of these molecules made levansucrase an attractive enzyme for applied research (Li, Yu, Zhang, Jiang, \& Mu, 2015). Although expression is usually induced by sucrose, levansucrase is constitutively expressed in some microbes living in sucrose-rich habitats (Toksoy Öner et al., 2016). To date, the three-dimensional (3D) structures of four levansucrases have been obtained: SacB from Bacillus subtilis subsp. subtilis 168 (Protein Data Bank [PDB] ID: 10YG), LdsA from Gluconacetobacter diazotrophicus SRT4 (PDB ID: 1W18), SacB from B. megaterium (PDB ID: 3OM2), and levansucrase from Erwinia amylovora (PDB ID: 4D47). As for the inulosucrases, the only 3D structure obtained to date belongs to InuJ from Lactobacillus johnsonii NCC533 (PDB ID: 2YFR).

Microbes contain different classes of specialized $\mathrm{GH} 32$ family hydrolases involved in fructan degradation. Invertases or $\beta$-fructofuranosidases (EC 3.2.1.26) hydrolyse preferentially or exclusively sucrose, but many forms are able to degrade fructans to a certain extent too. More specific fructan degrading enzymes include endo- and exo- type of levanases (EC 3.2.1.65 and EC 3.2.1.64, respectively) and inulinases (EC 3.2.1.7). As described below in further detail (see Section 3.3), some microbes use their levansucrases to degrade levans. These microbes lack specific levanases. Many different fungi employ various GH32 family hydrolases (Trollope, Wyk, Kotjomela, \& Volschenk, 2015; Van der Nest et al., 2015); however, there have been no reports on fungal GH68 enzymes. 3D structures of two different fungal inulinases from Aspergillus amawori (PDB ID: 1Y4W) and Aspergillus ficuum (PDB ID: 3RWK); and invertases / $\beta$-fructofuranosidases from Schwanniomyces occidentalis (PDB ID: 3KF5), Aspergillus kawachii (PDB ID: 5XH9), Saccharomyces cerevisiae (PDB ID: 4EQV), and Xanthophyllomyces dendrorhous (PDB ID: 5ANN) have been obtained so far. As for the bacteria, 3D structures of three different bacterial invertases or $\beta$-fructofuranosidases are available today, which were isolated from the following species: Bifidobacterium longum (PDB ID: 3PIG), Microbacterium saccharophilum (PDB ID: 3WPU), and Thermotoga maritima (PDB ID: 1UYP). Although different levanases have been isolated from some Bacillus and Bacteroides species (Mardo et al., 2017; Miasnikov, 1997; Pereira, Petit-Glatron, \& Chambert, 2001; Porras-Domínguez et al., 2014), the only 3D structure related to levanases is a carbohydrate binding module present at the $\mathrm{C}$-terminal end of $B$. subtilis exolevanase (CBM66; PDB ID: 4AZZ). This module seriously increases the enzymes' activity and substrate specificity towards levan-type fructans (Cuskin et al., 2012).

In plants, generally five types of fructans are described, synthesized by a set of different FTs (Figure 1b). Inulins (1) contain $\beta-2,1$ linkages and are mainly found in dicot species. The smallest inulin, 1-kestotriose, is formed after the addition of a fructose moiety from sucrose onto a second sucrose residue by sucrose:sucrose 1-fructosyltransferase (1-SST; EC 2.4.1.99). Higher DP inulins are formed through subsequent addition of fructose by fructan:fructan 1-fructosyltransferase (1-FFT; EC 2.4.1.100; Mensink, Frijlink, Maarschalk, \& Hinrichs, 2015a; Van Laere \& Van den Ende, 2002). Certain crops, such as chicory (Cichorium intybus) and artichoke (Cynara cardunculus), contain high amounts of inulin, and their prebiotic and direct immunomodulating effects in animals have been studied (Di Bartolomeo \& Van den Ende, 2015; Mensink, Frijlink, Maarschalk, \& Hinrichs, 2015b; Peshev \& Van den Ende, 2014; Roberfroid, 2005). In monocot fructans, $\beta-2,6$ linkages predominate. 6-Kestotriose and higher DP levans are synthesized through subsequent action of sucrose:sucrose 6-fructosyltransferase (6-SST; EC 2.4.1.-) and/or sucrose:fructan 6-fructosyltransferase (6-SFT; EC 2.4.1.10) activities (Van den Ende, 2013). Linear levan-type fructans (2) occur in fodder grasses such as Dactylis glomerata and Phleum pratense. Also, several members of the Poaceae, including wheat (Triticum aestivum), also produce a branched type of fructan, the graminans (3), involving 6-SFT and 1-FFT activities. Inulin neoseries (4) and levan neoseries (5) fructans are characterized by an internal glucose moiety due to the activity of a fructan:fructan $6^{\mathrm{G}}$ fructosyltransferases (6G-FFT; EC 2.4.1.243) and are found in onion (Allium cepa), oat (Avena sativa), and perennial rye-grass (Lolium perenne) among others (Livingston, Hincha, \& Heyer, 2009). Recently, the prebiotic effects of graminans and neoseries fructans have also been studied (López-Velázquez et al., 2015; Verspreet, Dornez, Van den Ende, Delcour, \& Courtin, 2015).

Fructan exohydrolases (FEHs), members of the GH32 family of enzymes, catalyse the hydrolysis of plant fructans by removing terminal fructose residues. Contrary to microbes, fructan endohydrolases are absent in plants (Van den Ende, De Coninck, \& Van Laere, 2004). In general, plant FEHs cannot degrade sucrose, so the help of different types of invertases is required to completely degrade fructans into hexoses (De Coninck et al., 2005). The 3D structure of a 1-FEH from chicory (Verhaest et al., 2004) and the crystal structure for the dual 6-SST/6-SFT enzyme from Pachysandra terminalis have already been obtained (Lammens et al., 2012).

Occasionally, more complex fructan types are being documented. In Agave plants (Agavaceae), a complex mixture of graminan-type fructans and neoseries fructans has been identified and characterized (López, Mancilla-Margalli, \& Mendoza-Diaz, 2003; Mancilla-Margalli \& López, 2006; Suárez-González, López, Délano-Frier, \& Gómez-Leyva, 2014). These so-called agavins (Figure 1c) are industrially produced in Mexico and show promising prebiotic effects (López-Velázquez et al., 2015; Moreno-Vilet et al., 2014). Wang, Hua, and Yan (2015) described a branched fructan containing $\beta-2,6$ and $\beta-2,1$ linkages in the dicot species Achyranthes bidentate, a Chinese medicinal plant belonging to the Amaranthaceae.

\subsection{Universality in fructan metabolism}

The universality among plant and microbial enzymes involved in the synthesis and degradation of fructans and in the degradation of sucrose is best explained by focusing on what all these enzymes actually do. Essentially, and in its broadest way of interpretation, all of them can be considered as (poly or oligo)fructosyltransferases (De Coninck et al., 2005), transferring a fructosyl moiety (or a fructosyl chain) from a donor substrate (fructan, sucrose) to an acceptor substrate (fructan, sucrose, or water) (Antošová \& Polakovič, 2001; De Coninck et al., 2005; Lammens et al., 2009). This view conceptually integrates all the above-mentioned enzymes within families $\mathrm{GH} 32$ and GH68, which together form the GH-J clan. Consistently, all GH-J clan enzymes exhibit classical Koshland retaining mechanism (Koshland \& 
Stein, 1954), and they are all marked by the fivefold $\beta$-propeller core structure, although the GH32 enzymes carry a $\beta$-sandwich consisting of six $\beta$-strands as an addition to this core (Lammens et al., 2009). Figure 1a,b provide an overview of the microbial and plant GH-J FTs involved in fructan synthesis and degradation.

It can be concluded that there are many similarities between microbes and plants when it comes to fructan metabolism, although multiple differences clearly exist. For instance, as opposed to plants, it is not yet well established that all microbes can degrade their synthesized fructans. The general structure of fructans is similar because both plant and microbial fructans contain the same types of glycosidic bonds (as well as physicochemical properties when identical DPs are compared). The overall structural fructan diversity in nature is huge. Microbial fructans generally have dominant high DP levan or inulin fractions with highly variable branching, but so far, no high DP neokestose-based levan or inulin series has been characterized from microbes. Plants lack such high DP fructans as occurring in microbes, but they are able to produce lower (to medium) DP inulin and levan neoseries by using a more extended set of FTs.

Regardless of their microbial or plant origin, all enzymes involved in fructan biosynthesis and degradation or mobilization belong to the $\mathrm{GH}-\mathrm{J}$ clan of glycoside hydrolases and share the same core structure and catalytic mechanisms with an aspartate and glutamate acting as catalytic nucleophile and general acid or base, respectively (Yanase et al., 2002). Nevertheless, at the organismal level, fructan metabolism differs greatly between microbes and plants, and their functions depend on external factors (the environment) as well. In Section 3, differences in fructan function and distribution as related to the environment will be discussed separately for microbes and plants before drawing general conclusions across both kingdoms.

\section{3 | MICROBIAL FRUCTANS}

\section{1 | Microbial fructans are exopolysaccharides (EPSs)}

All microbial fructans are produced by cell wall-associated or extracellular FTs. So, these fructans make part of a pool of extracellular polymeric carbohydrates, termed EPSs. EPSs are involved in multiple biological functions such as virulence, biofilm formation, energy storage, and protection from unfavorable environmental conditions. Those EPSs show a wide variety of different structures, from simple homopolysaccharides such as levan and curdlan to complex heteropolysaccharides composed of many different monomeric sugars such as gellan and xanthan. Moreover, microbial EPS production may involve a mixture of different polymers rather than just one type, such as the three different EPSs (Pel, Psl, and alginate) of Pseudomonas aeruginosa or coproduction of dextran and levan by Leuconostoc mesenteroides (Özcan \& Toksoy Öner, 2015). Table 1 shows some of the most common microbial EPSs in nature. EPSs are one of the vital components of microbial biofilms along with various extracellular proteins and extracellular DNA (eDNA), in which complex mutualistic and antagonistic relations between microbes are observed. Most EPSs have high intrinsic viscosity, contributing to the elastic behavior of biofilms. It is also known that horizontal gene transfer takes place inside the biofilm through eDNA, further highlighting the vital role of biofilm components in evolution (Flemming, 2011; Sørensen, Bailey, Hansen, Kroer, \& Wuertz, 2005).

EPSs in biofilms protect microbes from desiccation by increasing the water availability (Tamaru, Takani, Yoshida, \& Sakamoto, 2005). Chang et al. (2007) investigated the role of alginate in Pseudomonas putida biofilms under water-limiting conditions and observed that under such conditions, alginate caused a thicker and more compact biofilm structure with less surface area, probably preventing water loss due to evaporation. Inulin is known to be an important part of the biofilm produced by oral Streptococcus mutans, and inulin accumulating in dental plaques is hydrolysed when environmental carbon sources are scarce, which in turn may cause dental carries in the long run (Krzyściak, Jurczak, Kościelniak, Bystrowska, \& Skalniak, 2014). Nagasawa, Sato, and Senpuku (2017) studied the effects of sucrose and raffinose, a trisaccharide composed of D-galactose, D-glucose, and $\mathrm{D}$-fructose, on biofilm formation of $S$. mutans, and found that at sucrose concentrations insufficient to induce biofilm formation, raffinose contributed to biofilm structure by increasing aggregation of eDNA while also being a substrate for raffinose-based inulin production. Because the $\mathrm{D}$-glucose moiety in raffinose is located between the other two monosaccharides, glucosyltransferase enzymes cannot use raffinose as donor substrate to synthesize glucans. S. mutans inulosucrase, on the other hand, is able to utilize raffinose to produce raffinose-based inulins. In addition, it was also revealed that sucrose increased cell surface hydrophobicity, thus contributing to adhesion of cells to surfaces. Besides inulin, levan is also known to play important roles in microbial biofilms (Dogsa, Brloznik, Stopar, \& MandicMulec, 2013 and references therein). Levan, although not strictly essential for biofilm formation, forms a structural and possibly stabilizing component of B. subtilis biofilms (Dogsa et al., 2013). These authors proposed that the water-soluble characteristics and interactive properties of levan allow its cross-linking to protein TasA and to the EPS A-O polysaccharide, possibly contributing to thicker and more stable biofilms. Another conclusion of this work is that levan may serve as a nutritional reserve, to provide energy during starvation periods similar as proposed by Laue et al. (2006) for Pseudomonas syringae levan in biofilms. Moreover, it was noticed that both levan- and alginate-deficient $P$. syringae strains were still able to form biofilms via a third, unknown EPS (Laue et al., 2006). Thus, from a wider perspective, one cannot dismiss the fact that some of levan's functions may be replaced by other EPSs produced by the same or other microbes. In general, deeper studies on redundancy effects among different EPS fractions are warranted.

\section{2 | Microbial fructans in plant, soil, and viral context}

Intriguingly, some of the fructan-producing microbes have pathogenic or symbiotic relationships with plants. Zymomonas mobilis, G. diazotrophicus and Burkholderia pseudomallei have symbiotic relationships with Agave, sugarcane, and maize, respectively (Velázquez-Hernández et al., 2009). In a recent perspective paper (Versluys, Tarkowski, \& Van den Ende, 2017), the role of microbial fructans as microbe associated molecular patterns (MAMPs) in plant 
innate immunity has been discussed. In short, it was hypothesized that small hydrolytic products of microbial fructans may act as MAMPs and activate plant defense systems. Inferring from all the information given above, it is highly likely that symbiotic relationships between microbes and plants are one of the main driving forces for the evolution of microbial fructans. However, detailed studies are absent until now.

There are also fructan-producing microbes present in soil, such as B. subtilis, Rahnella aquatilis, and Paenibacillus polymyxa. Even though the role of fructans in their interactions with plants is still unclear, there are some hypotheses about that matter. Imam and Abd-Allah (1974) purified the fructan produced by Bacillus polymyxa AS-1 (today known as P. polymyxa) and used it as a soil conditioning agent to improve germination for Lupinus termis, Vicia faba, Zea mays and Sesamum indicum seeds in pots with sandy soil. The authors proposed that a $0.1 \%(w / w)$ levan or sandy soil mixture retained water by the hygroscopic nature of the levan. The authors indicated that their levan was able to absorb double its weight of moisture during night, when exposed to a humid atmosphere. Bezzate et al. (2000) reported that when wheat roots were inoculated with the nitrogen-fixing rhizosphere bacterium $P$. polymyxa, levan produced by the bacteria significantly increased the mass of root-adhering soil, which is an important factor for the growth and nutrition of cultivated plants. In conclusion, thanks to their hygroscopic and adhesive nature, microbial levans produced by soil microbes may have an important role in nutrient uptake as well as in retaining water in the rhizosphere and assuring water to reach seed or root surfaces contributing to seed germination and root-mediated water and nutrient uptakes.

An interesting study conducted by Daguer, Geissmann, Petit-Glatron, and Chambert (2004) revealed that different strains of the rhizosphere bacterium $B$. subtilis produced levan in the presence of high sucrose concentrations, followed by levan degradation to release levanbiose. However, it was observed that levanbiose could not be metabolized by $B$. subtilis strains, thus ruling out the possibility of levan being an energy storage for this bacterium. Being a small diffusible molecule, levanbiose was proposed by the authors to act as a signalling molecule that takes part in plant-microbe communication. By extension, levan oligosaccharides produced by microbial endolevanases could be involved in plant-microbe (Versluys et al., 2017) or microbe-microbe communication as well. The possibility that small fructans can act as signals has also been raised in the plant context (Van den Ende, 2013; see also below). In B. subtilis, expressions of levansucrase and levanase genes are tightly connected. Leloup, Petit-Glatron, Chambert, and Le Saux (1999) revealed that when B. subtilis levanase gene was expressed under the control of inducible levansucrase leader region, induction by sucrose resulted in overexpression of levanase during the exponential growth phase. Pereira et al. (2001) showed that sacB and yveB genes from B. subtilis, which encode levansucrase and endolevanase, respectively, are located in the sacB-yveB-yveA tricistronic operon, whose transcription is simultaneously stimulated by sucrose. In fact, because levansucrase and endolevanase are synthesized together, a synergistic action towards levan is proposed in the light of two facts, one being the exolevanase activity of levansucrase that is arrested at the branch points of levan, and the latter being the higher amounts of fructose released from the coaction of both enzymes when compared to the total fructose released by each enzyme separately. According to this view, the endolevanase activity is suggested to release additional sites on levan for fructose release by the exolevanase activity of the levansucrase enzyme (Pereira et al., 2001).

It is well-known that levan is an important component of the biofilm formed by phytopathogens such as $E$. amylovora and $P$. syringae, contributing to their virulence or survival (Koczan, McGrath, Zhao, \& Sundin, 2009; Laue et al., 2006). On the other hand, impaired proliferation of Myoviridae and Siphoviridae phages of an E. amylovora levansucrase knockout mutant indicates that these phages depended on levan produced by the host bacterium for their virulence (Roach, Sjaarda, Castle, \& Svircev, 2013). An in silico study conducted by Maaroufi and Levesque (2015) proposed the existence of GH32 enzymes in three different B. subtilis phages. The authors suggested that these enzymes act as exolevanases that release disaccharides from levan, thus potentially able to disrupt $B$. subtilis biofilms. It should be kept in mind that both levansucrase and levanase are already employed by $B$. subtilis to produce levan and then degrade it to levanbiose (Daguer et al., 2004). So the question is: do these phages actually need to secrete a levanase to survive? Or do they use this enzyme prior to $B$. subtilis producing its own levanase, so that bacterial biofilm formation can be disrupted at its early stages? Release of virus-infected bacteria from the disrupted biofilm in earlier stages could indeed be advantageous for these viruses to spread to other hosts. As Daguer et al. (2004) proposed that levanbiose may represent a signalling molecule for $B$. subtilis, the levanbiose formed by action of the viral enzyme on B. subtilis levan could mimic this process, suggesting the existence of a complex signalling cascade among the virus-bacterium-plant triad. In vitro validation of these hypotheses would enlighten more than what is suggested here. In conclusion, it appears that microbial fructans and signals derived thereof may be central players in pathogenic or symbiotic relationships between the above-mentioned triad.

\section{3 | Fructan syndrome in extremophiles}

Extremophilic archaea and bacteria dominate the most "uninhabitable" parts of nature, namely deep sea vents with exceptionally high temperatures and pressures, salt lakes with salt concentrations that would kill any mesophile instantaneously, or highly acidic, sulfur-rich geothermal areas. Along with adaptation to extreme conditions with mechanisms such as altered membrane compositions and accumulation of cytoplasmic compatible solutes (i.e., ectoine, betaine, and trehalose; Babu, Chandel, \& Singh, 2015), it is known that a significant number of these microbes also produce a wide variety of EPSs, and it is expected that EPSs potentially fulfil even more important functions in extremophiles as compared to mesophiles, to cope with high salinity or desiccation (both leading to extreme water scarcity), extreme temperatures (very high and very low), extreme pressure or $\mathrm{pH}$ levels, UV radiation, and so forth. Protective effects of these EPSs are mostly physical, forming a "shield" around these microbes, thus hindering the adverse effects of high salinity, UV, heavy metals, and so forth. Although a wide range of different EPSs produced by extremophiles have been characterized so far (Finore, Lama, Poli, Di 
Donato, \& Nicolaus, 2015), very little is known about extremophilic or extremotolerant fructan producing microbes (Table 2). This review intends to boost further research in this area.

First in 1957, Lindeberg isolated levan producing microbes from "ropy" herring brine. The microbes showed maximal growth at 1-2 M $\mathrm{NaCl}$ and were identified as gram-negative, aerobic, nonmotile, and nonspore forming rods that were classified as Achromobacter spp. Then, Magnússon and Möller (1985) isolated slime producing microbes from sugar-salted herring brine as well and identified them as gram-negative, aerobic, nonmotile, oxidase-positive, and halophilic (optimum growth at $10 \% \mathrm{NaCl}$ ) rods. As for the origin of these microbes, it was pointed out in their research that the wood scrapings from old, used wooden barrels that are used for the storage of herring brine contained high amounts of slime producing microbes. They suggested that the bacteria isolated by Lindeberg in 1957 were taxonomically weakly classified. They also indicated that the slime produced by their bacteria was mainly composed of fructose, as expected for levan. However, because the methods they used to identify the polysaccharide were not exhaustive and quantitative, they were skeptical of their results and have pointed out that other minor components in the polysaccharide could not be excluded.

It was not until 2009 that a moderately halophilic levan producer, Halomonas spp. AAD6T, was isolated from soil samples of Çamaltı Saltern area (Izmir, Turkey) and then successfully identified as a new species to be named as Halomonas smyrnensis AAD6T (Poli et al., 2009; Poli, Nicolaus, Denizci, Yavuzturk, \& Kazan, 2013). Another halophilic levan producer, Chromohalobacter japonicus BK AB18, was isolated from Bledug Kuwu mud crater (Purwodadi-Grobogan, Central Java, Indonesia) by Nasir, Wahyuningrum, and Hertadi (2015). The moderate halophile Bacillus licheniformis BK AG21 was also isolated from the same location by Wahyuningrum and Hertadi (2015). It should be noted that $B$. licheniformis strains are usually considered as halotolerants instead of halophiles, taking into account that they show better growth when there is no $\mathrm{NaCl}$ in the fermentation medium, but they can withstand salt concentrations up to $10 \%(w / v)$. In addition to that, most $B$. licheniformis strains can grow at temperatures up to $55^{\circ} \mathrm{C}$ (Rainey et al., 2009). Moreover, they also possess levanase enzymes that hydrolyse levan to monosaccharides or oligosaccharides, depending on the exo- or endo- type of the enzymes. The existence of both levansucrase and endolevanase activities in many $B$. licheniformis strains indicate that levan functions as a kind of storage carbohydrate in these microbes. However, it should be noted that most levansucrases also show intrinsic exolevanase activity in the presence of levan when sucrose is absent or very low. Intriguingly, exolevanase activity of levansucrases is limited to $\beta-2,6$ linkages, the enzyme being hindered when it reaches $\beta-2,1$ branching points on the levan chain (Méndez-Lorenzo et al., 2015; Toksoy Öner et al., 2016). In this case, encoding both levanase and levansucrase seems to be evolutionarily advantageous over encoding levansucrase only, for those microbes that would use previously synthesized levan as a storage carbohydrate (for instance, when the environment allows rapid reproduction and growth because of increased nitrogen provision but with limited carbon availability).

\subsection{1 | Predicted GH-J members in halophilic prokaryotes}

Although the mechanisms and characteristics of fructan accumulation in some plants under unfavorable conditions such as drought or cold are well established, the literature that evaluates fructan production by microbes in extreme conditions is much scarcer. Bioinformatic

TABLE 2 Studied extremophilic and extremotolerant levan producers

\begin{tabular}{|c|c|c|c|}
\hline Microbe & Habitat & & Reference \\
\hline Halophiles or halotolerants & & Optimum salt conc. (\%, w/v) & \\
\hline $\begin{array}{l}\text { Gram (-), aerobic, nonmotile, nonspore forming } \\
\text { rods ( } \mathrm{LS}^{\mathrm{a}}, \text { crude) }\end{array}$ & $\begin{array}{l}\text { Ropy herring } \\
\text { brine }\end{array}$ & 8.00 & Lindeberg (1957) \\
\hline Gram (-), aerobic, nonmotile, oxidase-positive rods & $\begin{array}{l}\text { Ropy herring } \\
\text { brine }\end{array}$ & 10 & Magnússon and Möller (1985) \\
\hline Halomonas smyrnensis AAD6T & $\begin{array}{l}\text { Soil from a } \\
\text { saltern area }\end{array}$ & 13.72 & Kazak Sarilmiser et al. (2015) \\
\hline Chromohalobacter japonicus BK AB18 & Mud crater & 7.5 & Nasir et al. (2015) \\
\hline Bacillus licheniformis BK AG21 & Mud crater & $1-5$ & Wahyuningrum and Hertadi (2015) \\
\hline Thermophiles or thermotolerants & & Optimum temperature $\left({ }^{\circ} \mathrm{C}\right)$ & \\
\hline Bacillus sp. TH4-2 (LS, purified) & Soil & $\begin{array}{l}60 \text { (hydrolysis), } 50 \text { (levan } \\
\text { formation) }\end{array}$ & Ammar et al. (2002) \\
\hline Bacillus sp. (LS, crude) & Thermal source & $\begin{array}{l}40 \text { (levan formation) } 50 \text { (enzyme } \\
\text { production) }\end{array}$ & $\begin{array}{l}\text { Belghith, Dahech, Belghith, and Mejdoub } \\
\text { (2012) }\end{array}$ \\
\hline Bacillus licheniformis (LS, partially purified) & Thermal source & 40 (enzyme production) & $\begin{array}{l}\text { Dahech, Belghith, Belghith, and Mejdoub } \\
\text { (2012) }\end{array}$ \\
\hline $\begin{array}{l}\text { Bacillus licheniformis RN-01 (LS, expressed in } \\
\text { Escherichia coli, purified) }\end{array}$ & $\begin{array}{l}\text { Soil of a hot } \\
\text { spring }\end{array}$ & 50 (levan formation) & $\begin{array}{l}\text { Nakapong, Pichyangkura, Ito, lizuka, and } \\
\text { Pongsawasdi (2013) }\end{array}$ \\
\hline $\begin{array}{l}\text { Geobacillus stearothermophilus ATCC } 7953 \text { (LS, } \\
\text { purified) }\end{array}$ & $\begin{array}{l}\text { Culture } \\
\text { collection }\end{array}$ & $\begin{array}{l}57 \text { (hydrolysis and } \\
\text { transfructosylation) }\end{array}$ & $\begin{array}{l}\text { Inthanavong, Tian, Khodadadi, and Karboune } \\
\text { (2013) }\end{array}$ \\
\hline Bacillus licheniformis NS032 & $\begin{array}{l}\text { Petroleum } \\
\text { sludge }\end{array}$ & 37 (levan formation) & Kekez et al. (2015) \\
\hline
\end{tabular}

Note. Concentration and temperature values indicate optimum values for levan formation. conc = concentration; LS = levansucrase.

aLS indicates that levansucrase enzyme of the bacterium was used for levan production. 
analysis in relevant databases revealed that $\mathrm{GH}-\mathrm{J}$ enzymes are predominantly present in wide genera of bacteria and in archaea belonging to Haloferacales, Halobacteriales, and Natrialbales orders.

Although there have been no studies about levan production by archaea to the best of our knowledge, archaea are the most extensively studied organisms regarding halophilic enzymes (or shortly, "halozymes"), especially Halobacteriaceae family (Madern, Ebel, \& Zaccai, 2000). Contrary to the absence of studies on archaeal GH-J enzymes, the National Center for Biotechnology Information database harbors more than 50 different archaeal strains that are annotated to carry GH-J genes in the orders Haloferacales, Halobacteriales, and Natrialbales, which are all moderate to extreme halophiles. As for the bacteria, moderately halophilic or halotolerant $\mathrm{GH}-J$ enzymes are predominantly present in orders Oceanospirillales, Vibrionales, and Bacillales. The mechanisms of adaptation of halozymes to highly saline environments are still not fully understood. However, there are certain characteristics of these enzymes: they usually have large numbers of acidic residues on the protein surface and decreased protein hydrophobicity, which are thought to increase those proteins' solubility and prevent their aggregation at high salinities (DasSarma \& DasSarma, 2015; Oren, 2013; Reed, Bushnell, \& Evilia, 2014). Zhang and Yi (2013) also suggested that halozymes exhibit a higher composition of some dipeptides such as DA, RA, AD, AP, RR, DD, VG, DV, PD, and EA at the expense of IL, II, IA, IS, KK, LK, KA, GK, RK, Al, and so forth. In light of these facts, 62 halophilic GH-J enzymes from abovementioned orders have been analysed in silico for this review for their composition of negatively and positively charged residues, as well as theoretical pl values (Table 3). Our homology modelling (SWISS-MODEL) approaches suggested that all selected $\mathrm{GH}-J$ enzymes (Table 3) belong to GH68, but with very uncertain functionality. Overall, computational prediction of functionality within $\mathrm{GH}-J$ remains troublesome, given the fact that sometimes a few amino acid changes alter functionality (Le Roy et al., 2013). Thus, future functional studies are required to unravel which forms may represent levansucrases and which forms may be $\beta$-fructofuranosidases.

As shown, the mean percentage of negatively charged residues for moderately halophilic GH-J enzymes of Oceanospirillales, Vibrionales, and Bacteriales orders are $14.16 \pm 1.12$; $13.27 \pm 0.63$; and $15.24 \pm 1.24$. On the other hand, these values for archaea from Haloferacales, Halobacteriales, and Natrialbales orders are $17.93 \pm 0.97 ; 16.79 \pm 0.85$; and $18.19 \pm 0.92$, respectively. The striking increase in the percentage of negatively charged residues in archaea is likely to be correlated with increasing salinity of their environments. As a rule, these archaea are extreme halophiles, whereas bacteria from above-mentioned orders are mostly moderate halophiles. Thus, it is clear that archaea employ more negatively charged residues on their $\mathrm{GH}-\mathrm{J}$ enzymes to ensure solubility in such high salt concentrations. Localization scores obtained from PSORTb 3.0.2 indicated that these archaeal GH-J enzymes were all predicted to be extracellular.

Paul, Bag, Das, Harvill, and Dutta (2008) evaluated different physicochemical characteristics of four sets of orthologous proteomes from halophiles and non-halophiles. It was revealed that in all cases, halophilic proteomes showed higher ratios of negatively charged residues (17-19\%) when compared with mesophiles (12-14\%). Additionally, Graziano and Merlino (2014) stated that even though homologous halophilic and nonhalophilic proteins are similar in terms of overall structures, halophilic proteins have lower numbers of nonpolar residues and higher numbers of charged residues on their surface. It can also be seen in Table 3 that archaeal GH-J enzymes have slightly lower $p l$ values compared to bacterial ones, which is a natural consequence of a higher number of acidic residues. It is well-known that halophilic proteomes exhibit significantly acidic $p /$ values, whereas mesophilic ones show a more even distribution, with most proteins at $\mathrm{pl}$ values near neutral $\mathrm{pH}$, and decreasing number of proteins with acidic and basic $p l$ values (Karan, Kumar, Sinha, \& Khare, 2012; Paul et al., 2008). As for the percentage of positively charged residues, there was no significant difference among organisms evaluated, except for Bacillales, which have a mean percentage of $8.74 \pm 0.57$. Interestingly, analysis of some halotolerant and thermotolerant Bacillales (genera of Bacillus, Geobacillus, and Brevibacillus) revealed that their GH-J enzymes have more or less close percentages of negatively and positively charged residues (11.83 \pm 0.48 and $11.31 \pm 0.93$, respectively). This might be due to the fact that most of these Bacillus species can also thrive in alkali conditions, with some of them being obligate alkaliphiles. Adaptation of bacterial and archaeal GH-J enzymes to changing salinities may indicate that these proteins are vital for their survival. However, this hypothesis requires experimental validation. Knocking out $\mathrm{GH}-\mathrm{J}$ genes in these microbes may prove useful for determining their importance for survival.

As indicated in the former paragraph, increase in percentage of negatively charged residues in halophilic proteins is not specific to GH-J enzymes, but it is observed throughout the proteome. So one may ask: If evolution needs to introduce modifications in all these enzymes in parallel to make them more functional at high salinities, probably some energetic considerations may put pressure on not keeping them all. Assuming that at least some of the forms (Table 3) encode genuine levansucrases, then why did these enzymes persist until today, and what could levans specifically offer as compared to alternative EPSs? The answer may be hidden in the simplicity of levan's biosynthesis as compared to most other EPSs. Biosynthesis of EPSs such as xanthan, pullulan, and curdlan involves five different steps: 1 . Uptake of monosaccharide units by the cell and their conversion to sugar nucleotides. 2. Formation of the repeating saccharide units on glycosyl carrier lipids. 3. Addition of acyl moieties. 4. Polymerization of the repeating saccharide units. 5. Secretion of the EPS to extracellular environment (Schmid, Sieber, \& Rehm, 2015; Sutherland, 1972). It seems that the only exceptions are fructans and a-glucans, which are synthesized directly from sucrose by single extracellular enzymes. aGlucans represent a wide variety of EPSs with different linkages between D-glucose units, namely dextrans, alternans, mutans, and reuterans (Leemhuis et al., 2013), and it is noteworthy to indicate that most of them are water-insoluble (Côté \& Skory, 2014; Sawada et al., 2015). Fructans, on the other hand, are all water-soluble and usually exhibit exceptionally low intrinsic viscosity values (Benigar et al., 2014; Carson, 2013). Interestingly, Lactobacillus reuteri 121 is known to have the genetic capacity to produce two fructans (levan and inulin) and two a-glucans (dextran and reuteran) (Kralj, van Geel-Schutten, Faber, van der Maarel, \& Dijkhuizen, 2005; Ozimek, Kralj, van der Maarel, \& Dijkhuizen, 2006). Inulin producer S. mutans expresses three additional soluble and insoluble a-glucans that contribute to the 
TABLE 3 Some physicochemical properties of halophilic GH-J clan enzymes

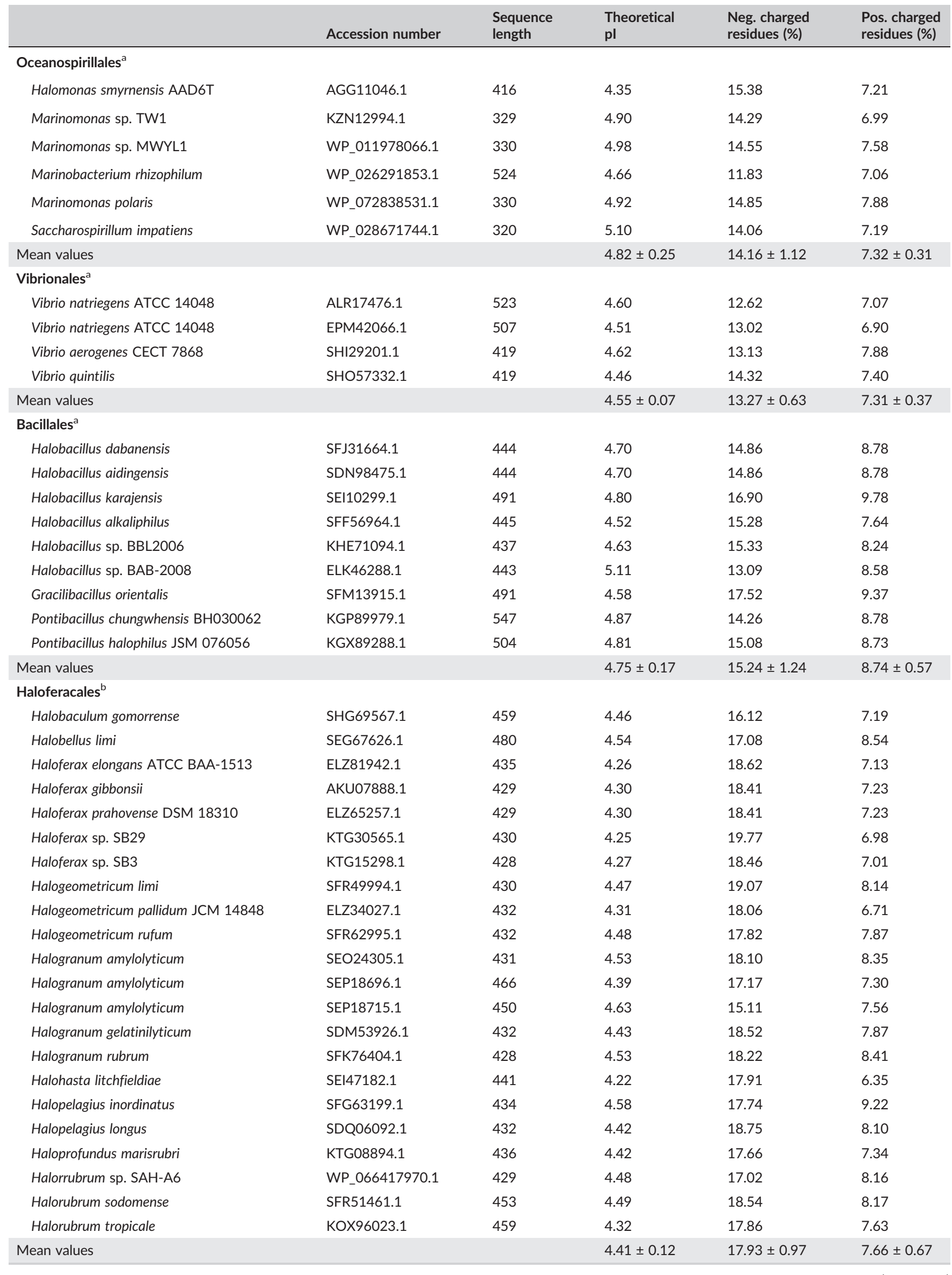


TABLE 3 (Continued)

\begin{tabular}{|c|c|c|c|c|c|}
\hline & Accession number & $\begin{array}{l}\text { Sequence } \\
\text { length }\end{array}$ & $\begin{array}{l}\text { Theoretical } \\
\text { pl }\end{array}$ & $\begin{array}{l}\text { Neg. charged } \\
\text { residues (\%) }\end{array}$ & $\begin{array}{l}\text { Pos. charged } \\
\text { residues (\%) }\end{array}$ \\
\hline \multicolumn{6}{|l|}{ Halobacteriales $^{\mathrm{b}}$} \\
\hline Haloarcula marismortui ATCC 43049 & AAV46403.1 & 445 & 4.54 & 16.85 & 8.09 \\
\hline Haloarcula hispanica ATCC 33960 & AEM57646.1 & 447 & 4.43 & 17.23 & 7.83 \\
\hline Haloarcula vallismortis ATCC 29715 & EMA01424.1 & 445 & 4.45 & 16.85 & 7.64 \\
\hline Haloarcula californiae ATCC 33799 & EMA09703.1 & 445 & 4.54 & 16.85 & 8.09 \\
\hline Haloarcula sinaiiensis ATCC 33800 & EMA16324.1 & 445 & 4.50 & 17.53 & 8.09 \\
\hline Haloarcula amylolytica JCM 13557 & EMA18083.1 & 447 & 4.42 & 17.23 & 7.61 \\
\hline Haloarcula argentinensis DSM 12282 & EMA18535.1 & 445 & 4.42 & 17.53 & 7.87 \\
\hline Haloarcula japonica DSM 6131 & EMA32821.1 & 444 & 4.42 & 17.12 & 7.21 \\
\hline Haloarcula rubripromontorii & KOX91943.1 & 442 & 4.45 & 17.19 & 7.69 \\
\hline Haloarcula sp. K1 & KZX49158.1 & 445 & 4.49 & 16.85 & 8.09 \\
\hline Halalkalicoccus paucihalophilus & KYH24232.1 & 451 & 4.30 & 15.96 & 5.54 \\
\hline Halalkalicoccus jeotgali B3 & ADJ14334.1 & 428 & 4.71 & 16.36 & 9.35 \\
\hline Halomicrobium zhouii & SFR97045.1 & 425 & 4.26 & 18.12 & 5.65 \\
\hline Halomicrobium mukohataei DSM 12286 & ACV48051.1 & 436 & 4.51 & 15.83 & 7.34 \\
\hline Haladaptasus litoreus & SIR87912.1 & 444 & 4.57 & 14.19 & 7.43 \\
\hline Haladaptatus paucihalophilus DX253 & EFW91340.1 & 431 & 4.59 & 17.17 & 9.51 \\
\hline Haladaptatus sp. R4 & KZN23362.1 & 433 & 4.53 & 16.63 & 8.55 \\
\hline Mean values & & & $4.48 \pm 0.10$ & $16.79 \pm 0.85$ & $7.74 \pm 0.99 \mathrm{~s}$ \\
\hline \multicolumn{6}{|l|}{ Natrialbales $^{\text {b }}$} \\
\hline Natronococcus occultus SP4 & AGB39317.1 & 454 & 4.41 & 18.72 & 8.59 \\
\hline Natronococcus amylolyticus DSM 10524 & ELY54148.1 & 459 & 4.35 & 18.95 & 7.84 \\
\hline Natronococcus jeotgali DSM 18795 & ELY66219.1 & 444 & 4.42 & 18.47 & 8.33 \\
\hline Halostagnicola kamekurae & SFT07523.1 & 451 & 4.35 & 16.63 & 6.21 \\
\hline Mean values & & & $4.38 \pm 0.03$ & $18.19 \pm 0.92$ & $7.74 \pm 0.93$ \\
\hline
\end{tabular}

Note. For negatively and positively charged residues, total number of (Asp + Glu) and (Arg + Lys) residues in each protein sequence were taken into account by ExPASy ProtParam tool, respectively. $\mathrm{GH}$ = glycoside-hydrolase; neg. = negative; pos. = positive.

${ }^{\mathrm{a}}$ Eubacteria.

${ }^{\mathrm{b}}$ Archaea.

formation of virulent plaque by playing different but overlapping roles (Bowen \& Koo, 2011). Besides these, Weissella confusa is known to produce both inulin and dextran, whereas Leuconostoc citreum is able to produce inulin, dextran, and alternan (Maina, Tenkanen, Maaheimo, Juvonen, \& Virkki, 2008). Coproduction of glucans and fructans suggest intersecting functional roles of these polymers. Water-solubility and energy cost of the EPSs biosynthesis route could be important factors in microorganisms' EPSs profile. To get a clearer picture of the selection pressures that gave rise to the presence of various EPSs in bacteria and archaea, more detailed investigations that intensely focus on this matter are required.

\section{4 | FRUCTANS IN PLANTS}

Fructans are one of the main storage carbohydrates in plants, found in ca. $15 \%$ of plant species (Hendry, 1993), mainly in the families Asteraceae, Campanulaceae, and Boraginaceae (dicots) as well as in the Poaceae and Liliaceae (monocots; Van den Ende et al., 2004; Livingston et al., 2009). Although their main function is to bridge the gap between resource availability and demand, several other functions have been described, including membrane stabilization and radical scavenging during abiotic stress (Hincha et al., 2007; Matros, Peshev, Peukert, Mock, \& Van den Ende, 2015). Fructans harbor a more flexible structure as compared to starch, characterized by $-\mathrm{O}-\mathrm{CH}_{2}$-linked furanose rings. Nevertheless, flexibility differs for each fructan type, for example, inulin-type fructans are more flexible than levan-type fructans. Although in dicots fructans usually accumulate as long-term storage carbohydrate in underground organs, they often function as short-term reserve compounds in Poaceae (Valluru \& Van den Ende, 2008). In perennial grasses, however, they may function as long-term reserve carbohydrates to survive the winter period (Hendry, 1993). Fructan synthesis starts within the vacuolar compartment, where FTs transfer fructose residues from one sucrose onto another sucrose and onto fructans, producing fructose-based oligo- and polysaccharides (Figure 1b; Livingston et al., 2009). Fructan structure and DP are species- and tissue-specific, due to differences in FTs. Therefore, fructan structure is not directly correlated to plant taxonomy (Bonnett, Sims, Simpson, \& Cairns, 1997). 
As mentioned before, contrary to microbes, fructan endohydrolases are absent in plants. Plants produce different types of FEHs to mobilize their fructan reserves. 1-FEHs (EC 3.2.1.153) hydrolyse $\beta-2,1$ linkages, whereas 6-FEHs (EC 3.2.1.154) degrade $\beta-2-6$ linkages. Other FEHs that hydrolyse both linkage types have also been characterized (Van den Ende et al., 2004). Interestingly, FEHs have been described in nonfructan plants as well, where 6-FEH is more common than 1-FEH (De Coninck et al., 2005; Van den Ende, De Coninck, Clerens, Vergauwen, \& Van Laere, 2003). Although the role of FEHs in these plant species is not entirely clear, a possible function in microbial disease resistance (Van den Ende et al., 2004) or in regulation of cell wall invertase activity (Le Roy et al., 2013) has been hypothesized. Another view is that these FEHs would be involved in fructan signalling (Versluys et al., 2017). From an evolutionary point of view, FTs and FEHs have evolved from vacuolar invertases and cell wall invertases, respectively. The presence of FEHs in the apoplastic environment, as well as in nonfructan plants, supports this idea (Valluru \& Van den Ende, 2008). The evolutionary origin of fructan synthesis, however, is difficult to predict, and the ability to synthesize fructans, the fructan syndrome, probably arose multiple times in the plant lineage (Van den Ende, 2013).

\subsection{Fructans and (a)biotic stress}

Plant fructan metabolism is known to be tightly linked to cold and drought tolerance. During abiotic stress, low DP fructans often accumulate, either through FEH-based fructan hydrolysis or FT-related synthesis (Arbillot, Gonzalez, Fontaine, \& Boucaud, 2009; Tarkowski \& Van den Ende, 2015). During mild abiotic stress, although plant growth is more affected than photosynthesis, increased sucrose levels boost both FT gene expression and FT enzymatic activities (De Roover, Vandenbranden, Van Laere, \& Van den Ende, 2000). In dicots, the complex regulation of fructan metabolic enzymes is not only influenced by abiotic stresses but also by the overall sugar and hormonal status of the plant (Valluru \& Van den Ende, 2008). In Agave tequilana and Agave inaequidens (Agavaceae), different sugar and phytohormone treatments induced an increase in FOS content. In response to treatment with abscisic acid $(50 \mathrm{mM})$, a central player in abiotic stress responses (Mehrotra et al., 2014; Sah, Reddy, \& Li, 2016), a significant accumulation of low and high DP FOS was measured due to the increased expression levels of 1-FFT or 1-SST genes (Suárez-González et al., 2014). A similar study in chicory (Asteraceae) showed an increase in FOS content after abscisic acid treatment. This increase involved de novo synthesis of new fructans from sucrose as well as degradation of higher DP fructans. In taproots of 6-week-old chicory seedlings, FOS content slightly decreased after transfer to a cold room $\left(6^{\circ} \mathrm{C}\right)$, associated with an increased expression of $\mathrm{FEHs}$ and invertases and a reduction in 1-SST and 1-FFT gene expression (Le Roy, Lammens, Van Laere, \& Van den Ende, 2008; Wei et al., 2016). However, Van den Ende and Van Laere (1996) showed an increased activity of 1-FFT in roots of older chicory plants.

\subsection{1 | Cold stress}

Cold stress, especially freezing, and water deficit can cause major damage to the plant cell membrane, one of the main sites of injury. Cold and drought tolerance in resistant plant species is often related to the modification of cellular components, with a central role for membrane-associated proteins (Jarzyniak \& Jasiński, 2014; Takahashi, Li, Nakayama, Kawamura, \& Uemura, 2013). Livingston, Knievel, and Gildow (1994) measured an increase in fructan content, mainly 1-kestotriose and $6^{G}$-kestotriose, in cold-hardened oat (Poaceae) stems. Because of the greater flexibility as compared to starch, fructans can insert between the lipid head groups of the cell membrane bilayer to prevent freezing damage. It has been speculated that a mixture of high DP and low DP fructans, produced as a results of stress-induced FEH activity, provides better membrane protection and stabilization. In order to interact with the outer part of the cell membrane, fructans have to be transported from the vacuole to the apoplast. Livingston and Henson (1998) measured an increase in apoplastic hexoses and fructans after subzero acclimation in winter oat, supporting a direct role during freezing and dehydration tolerance. Although the exact mechanism is still unclear, a vesicular pathway has been proposed (Valluru, Lammens, Claupein, \& Van den Ende, 2008) but not yet further confirmed since then.

Several reports have shown a possible link between fructan accumulation during cold stress and disease resistance. Winter wheat (Poaceae) cultivars resistant to snow molds (psychrophilic fungi that infect plants under snow) accumulate large amounts of carbohydrates before snow cover, including graminan-type fructans (Gaudet \& Laroche, 1997; Iriki et al., 2005). Winter wheat plants metabolize graminans under persisting snow. Snow mold-resistant cultivars are characterized by a high accumulation and lower metabolization rate under snow (Kawakami \& Yoshida, 2012; Yoshida, Abe, Moriyama, \& Kuwabara, 1998). In other words, FEH expression in resistant cultivars must be lower during snow cover in winter to ensure a slow metabolization rate, as confirmed by Meguro-Maoka and Yoshida (2016).

The potential role for plant fructans in such cross-tolerance mechanisms in fructan accumulators and nonfructan accumulators has recently been proposed (Versluys et al., 2017 and references therein). In fructan accumulators, exposure to mild (a)biotic stresses could release a mixture of fructans potentially acting as damage-associated molecular patterns, priming neighboring cells. In nonfructan accumulators, exogenous fructan may be perceived as MAMPs (Versluys et al., 2017). Lower dosages of fructans may act as signals and priming agents, causing a higher disease tolerance due to a faster and/or more prominent response to future stresses (Conrath, 2015). However, fructan receptors are not yet identified in plants, which is also the case for sucrose and T6P signals. In animals, inulin signals are sensed by Toll-like receptors (Franco-Robles \& López, 2015; Vogt et al., 2013).

Fructan immune signalling ideas fit under the umbrella of so called "sweet immunity" concepts (Bolouri Moghaddam \& Van den Ende, 2012). Small sugars such as sucrose, glucose, and cellobiose may be considered as damage-associated molecular patterns, at least under certain circumstances (Duran-Flores \& Heil, 2016; Heil, 2009; Souza et al., 2017). Small sugar signals, particulary sucrose and T6P signals, are intimately connected to starch build-up and degradation during the diurnal cycle (Seki et al., 2017; Sulpice et al., 2014), not only closely linked to growth dynamics but most probably also to diurnal stress reponses (Wang et al., 2011).

Fructans released into the apoplast (endogenous or exogenous origin) may be subject of partial degradation by FEHs, with a possible 
increased eliciting potential for FOS as compared to longer DP fructans. Because microbial fructans, mostly levans, are often characterized by high DP, FEHs may play a crucial role in their degradation to FOS and function as MAMP. This can explain why FEHs have also been found in nonfructan plant species and why these are, as far as we know for the moment, only of the 6-FEH type (De Coninck et al., 2005; Van den Ende et al., 2004; Versluys et al., 2017). Thus, it should be noted that exogenous fructan application (e.g., leaf spraying) may potentially lead to FOS and fructose production. If this is the case, it would be necessary to discriminate between FOS and fructose signalling (Cho \& Yoo, 2011; Li et al., 2011), a challenging task. Moreover, as it is the case in animals, fructan and FOS may act through direct (receptor-mediated signalling) or indirect (prebiotic effects on microbes) mechanisms (Peshev \& Van den Ende, 2014), complicating things.

The release of fructans in response to abiotic stress most likely depends on the partial degradation of high DP polysaccharides by FEHs, and a decrease in DP can often be observed after exposure to cold stress. As opposed to the situation in microbes, where fructan genes are sometimes constitutively expressed, they are induced at the onset of stress exposure in plants. Therefore, although microbial fructans may be involved in integral survival at persistent extreme conditions, most plants are usually not subjected to continuous extreme conditions, so a presumptive fructan-related protective function under stress is only induced after the occurrence of stress. In burdock (Arctium lappa, Asteraceae), the hydrolysis of inulin to FOS is strongly induced at $0{ }^{\circ} \mathrm{C}$ (Ishigura, Ueno, Onodera, Benkeblia, \& Shiomi, 2011). Although Livingston and Henson (1998) measured an increase of fructans in the apoplast of winter oat after subzero acclimation, a simultaneous rise in apoplastic FEHs was also measured. Other advantages of fructans during cold stress include high water solubility and, when compared to starch, reasonable biosynthetic rates at lower temperatures (Valluru \& Van den Ende, 2008). Additionally, a direct antioxidative effect through nonenzymatic radical scavenging reactions at the inner side of the tonoplast and the vacuolar lumen has been proposed (Matros et al., 2015; Peshev, Vergauwen, Moglia, Hideg, \& Van den Ende, 2013; Peukert et al., 2014).

\subsection{2 | Drought and other abiotic stress}

Presumptively, fructans protect plant cells in a similar way during drought exposure. In several perennial grasses, cell membrane stability was positively correlated with fructan content during severe drought. Most of the studied species native to upland grasslands could survive extreme drought exposure (Zwicke, Picon-Cochard, Morvan-Bertrand, Prud'homme, \& Volaire, 2015). Robe and Griffiths (2000) investigated the adaptations of Littorella uniflora (Plantaginaceae) during the transition from a freshwater environment to dry land, with a focus on storage carbohydrates. The authors showed an increase in soluble sugar, starch, and fructan content.

Species from the Asteraceae family accumulating high DP inulins, such as Viguiera discolor and Echinops ritro, have a higher drought tolerance as compared to lower DP accumulators (Van den Ende et al., 2005, 2006). In a similar fashion, some monocots, such as Dactylis and Lolium species in the Mediterranean, synthesize high DP levan-type fructans, partially explaining their ability to survive the severe drought periods associated with this area (Maleux \& Van den Ende, 2007; Volaire, Thomas, \& Lelievre, 1998). In V. discolor, Oliveira, Silva, Zaidan, and Carvalho (2013) tested the influence of high $\mathrm{CO}_{2}$ levels (760 ppm) on drought tolerance, showing a more prolonged presence of hexoses and low DP fructans, probably as a result of elevated levels of photosynthesis. Recently, the authors investigated this positive relation in a different species, Chrysolaena obovata (Asteraceae), and came to similar conclusions (Oliveira, Silva, \& Carvalho, 2016).

A convoluted role for fructans in barley grain has been suggested by Peukert et al. (2014), and this can probably be extended to wheat and other cereals (Verspreet et al., 2017). During the prestorage phase, levan and graminan synthesis supports cell division activities by reducing available sucrose levels. The start of the grain storage phase is characterized by a shift towards inulin-type fructan biosynthesis, due to changes in fructan biosynthetic enzyme expression. Although a role for these inulins in radical scavenging seems apparent, their intrinsic water retention properties may also be important during the natural period of drought that these grains are subjected to, which is a natural phase in their developmental cycle.

A recent manuscript by Blanch, Dolores Alvarez, Sanchez-Ballesta, Escribano, and Merodio (2017) shows evidence for the correlation between water deficiency and fructan synthesis in lettuce (Lactuca sativa var. Maravilla de Verano; Asteraceae). Moderate water deficit increased the production of nystose and kestopentaose among other responses, thus leading to a higher firmness of the plants and potentially higher resistance against low-temperature stress. It would be interesting to use CRISPR-Cas9 technology (Bortesi \& Fischer, 2015) to switch off the lettuce 1-SST gene and evaluate the effects of moderate drought stress in the absence of fructan biosynthesis. These experiments could provide us with more insight into fructan functionality during stress exposure and how the plant's stress response is disorganized in the absence of fructan production.

In another manuscript, AbdElgawad et al. (2014) suggest a role for fructans in overall cellular homeostasis. The effects of climate change were tested during drought exposure, comparing the fructan accumulating grasses L. perenne and Poa pratensis (both Poaceae) with the nonfructan accumulators Medicago lupulina and Lotus corniculatus, two nitrogen fixing legumes (Fabaceae). Drought exposure under elevated temperatures $\left(+3{ }^{\circ} \mathrm{C}\right)$ and $\mathrm{CO}_{2}$ concentrations $(620 \mathrm{ppm})$ caused an increase in fructan content in the grasses, whereas total carbohydrate content remained unchanged. Total carbohydrate content and overall tissue composition ( $\mathrm{C}$ and $\mathrm{N}$ content, minerals, and secondary metabolites) changed significantly in the legumes, whereas tissue composition in fructan accumulating grasses was unaffected, suggesting a less severe quality loss due to climate change in the latter.

Lolium species are often used as a model plant for fructan research (Lasseur et al., 2006, 2011; Lothier, Van Laere, Prud'homme, Van den Ende, \& Morvan-Bertrand, 2014), and the effects of other types of stresses have been documented. Lasseur et al. (2007) showed a stronger induction in FT activity and gene expression in L. perenne exposed to frequent defoliation, whereas Sandrin, Figueiredo-Ribeiro, Delitti, and Domingos (2013) linked daily oscillations in fructan content with tolerance to changes in weather and air pollution in Lolium multiflorum. Interestingly, although fructans are often associated with drought tolerance, Albrecht, Biemelt, and Baumgartner (1997) showed 
an increase in fructan content in response to flooding. Senecio aquaticus (Asteraceae) and Myosotis palustris (Boraginaceae), species found in areas prone to flooding and concurrent oxygen deficiency, were compared to close relatives from areas with low risk of flooding (Senecio jacobaea and Myositis arvensis). Fructan content increased up to tenfold under hypoxic conditions, whereas minimal changes in small sugars were measured. Although all species showed an increase in fructans, higher absolute values were measured in tolerant species often exposed to flooding. It was suggested that the storage of fructans as reserve carbohydrates is more advantageous than starch accumulation in light of oxygen deficiency tolerance (Albrecht et al., 1997; Albrecht \& Biemelt, 1998).

Although a clear role in abiotic stress tolerance has been proposed, it should be mentioned that there are alternatives to fructans within this context as many nonfructan accumulating plant species also survive these environmental conditions. An intriguing example can be found within resurrection plants, such as Selaginella lepidophylla. These plants can survive extreme desiccation. An important role for the carbohydrate trehalose in drought tolerance has been confirmed for these plants. This illustrates that nature provides different strategies to survive periods of water shortage and, although the role of fructans in abiotic stress tolerance should not be underestimated, we must also be cautious not to overestimate their importance (Dinakar \& Bartels, 2013; Zhang, Song, \& Bartels, 2016). Of course, the same reasoning holds true for the microbial world. For instance, the function of trehalose in desiccation tolerance has been investigated in the yeast Saccharomyces cerevisiae (Tapia \& Koshland, 2014).

\subsection{3 | Transgenic plants carrying microbial and plant FTs}

Interestingly, in the first studies, microbial enzymes were transgenically expressed in plants (Ritsema \& Smeekens, 2003; Vijn \& Smeekens, 1999). Transformation of both tobacco (Nicotiana tabacum) and sugar beet (Beta vulgaris) with a SacB levansucrase gene from $B$. subtilis has been studied, and the presence of levans was verified in transgenic plants. In both systems, an increased biomass production was observed under drought stress compared to control plants; however, under unstressed conditions, there was no significant increase in biomass production (Pilon-Smits et al., 1995; Pilon-Smits, Terry, Sears, \& van Dun, 1999). Using the same SacB gene, transgenic expression has also been tested in potato plants (Solanum tuberosum; Pilon-Smits et al., 1996). The introduction of fructan synthesis in these plants often coincides with an increased tolerance to abiotic stresses (Cairns, 2003; Keunen, Peshev, Vangronsveld, Van den Ende, \& Cuypers, 2013).

In order to further characterize and confirm the role of fructans in abiotic stress tolerance, genes involved in plant fructan biosynthesis have been transgenically expressed in nonfructan accumulating species (van Arkel et al., 2013 and references therein), such as Paspalum notatum (Muguerza et al., 2013), B. vulgaris (Matsuhira et al., 2014), and Brachypodium distachyon (Tamura et al., 2014). A significant positive effect on stress tolerance was observed in several studies. In tobacco (N. tabacum), electrolyte leakage in transgenic leaves expressing a lettuce (L. sativa) 1-SST gene was significantly reduced after $18 \mathrm{~h}$ at $-2^{\circ} \mathrm{C}$, although overall fructan content was extremely low (Li, Yang, Zhang, Gao, \& Zhang, 2007). The introduction of two wheat 1-SST genes caused strong fructan synthesis in rice (Oryza sativa) and enhanced chilling tolerance (Kawakami, Sato, \& Yoshida, 2008). In another study, after the incorporation of a 6-SFT from Bromus pictus (Poaceae) in tobacco, electrolyte leakage was significantly lower in leaves of transgenic plants when compared to controls after freezing (Del Viso et al., 2011). Interestingly, Hisano et al. (2004) showed that the overexpression of wheat 1-SST and 6-SFT in L. perenne, a fructan accumulator, strongly increased freezing tolerance on a cellular level.

These experiments may thus prove important in future agriculture to produce more stress tolerant transgenic crops. An alternative strategy includes the exogenous application of fructans by means of priming. Spraying the leaves with plant- or microbe-derived fructans may induce a state of readiness in the plant, allowing a faster and stronger response to future (a)biotic stresses (Martinez-Medina et al., 2016; Trouvelot et al., 2014; Versluys et al., 2017).

\section{2 | Biogeographical fructan distribution}

Generally, inulins are found in dicot species, whereas levans and graminans are found in monocots. However, the dicot $P$. terminalis (Buxaceae) accumulates graminans and levans (Lammens et al., 2012; Van den Ende et al., 2011). Notably, another member of this family, Buxus sempervirens, produces inulin FOS and raffinose family oligosaccharides (RFOs; Van den Ende, Coopman, Vergauwen, \& Van Laere, 2016), clearly indicating the potential structural diversity in reserve carbohydrates within one plant family. These RFOs, next to fructans, are the most important water-soluble carbohydrates in plants and are also known to be involved in abiotic stress tolerance (Sengupta, Mukherjee, Basak, \& Majumder, 2015; Tarkowski \& Van den Ende, 2015).

In the last few decades, the presence of fructans in many different plant species has been investigated. Sims (2003) quantified the fructan content in underground organs of Arthropodium cirratum, Astelia banksii, Bulbinella hookeri, Dianella nigra and Xeronema callistemon in New Zealand (Asparagales). Fructans are often found in large concentrations in underground storage organs of geophytes such as Galanthus nivalis (Amaryllidaceae) and Allium species (Alliaceae), where they can constitute more than $40 \%$ of the dry mass (Orthen \& Wehrmeyer, 2004; Ranwala \& Miller, 2008). In Curcuma kwangsiensis (Zingiberaceae), Dong et al. (2015) identified levan-type fructans (average DP $30-31$ ) with single fructose side chains ( $\beta-2,1$ linkage) and significant immunostimulating activity based on phagocytosis and macrophage proliferation assays. Moreover, inulin-type fructans from Pfaffia glomerata (Amaranthaceae) roots were shown to have prebiotic effects (Caleffi et al., 2015). Cruz-Cárdenas et al. (2015) showed the presence of inulin neoseries fructans and inulo- $n$-oses, fructose-only versions (Fn type fructans) lacking the terminal glucose residue (Van den Ende, 2013), in bananas (Musaceae).

In the past general correlations between the distribution of fructan accumulating plant species and environmental factors were investigated, contrary to the very limited research on microbial fructan distribution. Hendry (1993) concluded that their distribution is often linked to water shortage and cold in particular. Indeed, fructan accumulators are often found in dry and cold environments, but they are less common or absent in tropical and warmer regions. In tropical and subtropical grasses, starch and sucrose are the main storage 
carbohydrates, whereas fructans are more prominent in temperate grass species (Livingston et al., 2009). A study by Jensen, Harrison, Chatterton, Bushman, and Creech (2013) showed significantly higher fructan levels in cool season grasses such as $L$. perenne and A. cristatum as compared to warm-season grasses.

The Poaceae form the main component in about $20 \%$ of global vegetation, mostly in warm to cool temperate zones (BouchenakKhelladi, Verboom, Savolainen, \& Hodkinson, 2010). Fructan accumulators of the Liliales thrive in dry regions, and members of the Agavaceae are widespread in arid subtropical zones (Givnish et al., 2016; Vinnersten \& Bremer, 2001). The Asteraceae are well-represented in most regions except tropical rainforests (Simpson, 2010). On a smaller ecological scale, fructan accumulating plants cover a wide variety of biomes. Interestingly, they are mainly present within the evolutionary most advanced families, such as Asteraceae and Poaceae that are also some of the largest plant families in terms of species (Bouchenak-Khelladi et al., 2010; Simpson, 2010). These correlations are less clear for fructan-producing microbes.

The fructan literature contains several more recent studies that connect with the hypothesis of Hendry (1993). Jiang, Watkins, Liu, Yu, and Luo (2010) showed the potential involvement of proline and fructan biosynthesis, more specifically 1-FFT activity, in drought tolerance in prairie junegrass (Koeleria macrantha, Poaceae). Chamaescilla corymbosa (Asparagaceae) is a fructan-producing perennial geophyte that can survive on rocky soils in a Mediterranean climate (Shane \& Pate, 2015). Myrothamnus flabellifolia, a xerophytic resurrection plant of the Myrothamnaceae, survives on arid mountain ranges characterized by strong temperature fluctuations and a long dry season (Moore, Lindsey, Farrant, \& Brandt, 2007). Engelhardt, Petereit, Lechtenberg, Liefländer-Wulf, and Hensel (2016) measured the presence of fructans $(2.1 \%)$ in upper aerial parts and leaf tips of M. flabellifolia.

\subsection{1 | Biogeographical differences with nonfructan species}

In the past, researchers often investigated the involvement of fructans in stress tolerance by comparison to closely related nonfructan accumulators. In Patagonia, B. pictus, a native grass species subjected to drought and freezing showed constitutive fructan synthesis. However, this is an exception and has not been documented for other plant species so far. Bromus auleticus, a close relative normally growing in warmer climates, only accumulated fructans during cold exposure (Del Viso, Puebla, \& Hopp, 2009; Puebla, Salerno, \& Pontis, 1997). Thorsteinsson, Harrison, and Chatterton (2002) tested the response to cool temperatures in two cultivars of $P$. pratense. Vega, an Scandinavian cultivar, contained significantly higher fructan content as opposed to Climax, a cultivar grown in more temperate southern climates. In P. pratensis, fructan metabolism genes were investigated in three varieties during cold acclimation. Although fructan content increased in all varieties, transcription rates of FEH genes were several folds higher in the variety from Norway, as compared to those from Denmark and the Netherlands (Rao, Andersen, Dionisio, \& Boelt, 2011). Abeynayake et al. (2015) investigated biogeographical fructan differences in the grass species $L$. perenne. The ecotype Falster, adapted to a cold climate, had a stronger increase in fructan content, characterized by a higher overall proportion of high DP fructans, as compared to ecotype Veyo, found in warmer areas. These results show that fructan accumulation can be an adaptation to stressful environmental conditions and an important factor influencing the biogeographical distribution of these species.

In another comparison study, storage carbohydrates were investigated in 37 Australian alpine species. In 32 species, fructan was the main reserve carbohydrate, linked to alpine conditions and annual regeneration (Tolsma, Read, \& Tolhurst, 2007). In a follow-up experiment in Poa fawcettiae Vickery (Poaceae), fructan reserves increased significantly under cold treatment. The vegetative regeneration capacity after cold treatment or fire was clearly linked to fructan storage (Tolsma, Tolhurst, \& Read, 2010). In a recent study in the Himalayas, morphological and physiological differences between subnival species, found in the highest regions under the snow zone, and alpine species, stretching from the lower border of the subnival zone to the tree line, were compared in light of climate change and global warming. Dolezal et al. (2016) predict a complex, multidimensional change in lateral plant distribution with the rise in global temperatures. Subnival species, although having similar starch levels, contained up to $76.1 \%$ more fructans in roots than alpine species, suggesting an important role for fructans in altitudinal zonation of plant species. However, maybe the most illustrative example was indicated by Piotrowicz-Cieslak, Gielwanowska, Bochenek, Loro, and Górecki (2005), who measured and characterized the carbohydrate content in Colobanthus quitensis (Caryophyllaceae) and Deschampsia antarctica (Poaceae), the only two flowering plants of Antarctica and thus the most southern dicot and monocot species, respectively. Kestose FOS were present in D. antarctica, and RFOs are the main storage carbohydrate in $C$. quitensis and constitute over $50 \%$ of the total soluble carbohydrate pool in this species (Piotrowicz-Cieslak et al., 2005).

\subsection{2 | The Brazilian Cerrado}

A geographical region that has frequently been studied in the context of fructan research is the Cerrado in Brazil (Ratter, Ribeiro, \& Bridgewater, 1997). In a survey by Tertuliano and Figueiredo-Ribeiro (1993) the presence of inulin-type fructans was detected in ca. $80 \%$ of all examined species. Vernonia herbacea, a representative of the Asteraceae, stores high amounts of fructans; the bulk of which is stored in underground rhizophores. Low DP fructans accumulated during low-temperature periods, accompanied by a rise in 1-FEH activity and gene expression (Asega, Nascimento, \& Carvalho, 2011). However, the wide occurrence of fructans in the Cerrado is also linked to seasonal drought, as investigated in V. herbacea by Garcia, Asega, Silva, and Carvalho (2011). Oliveira-Joaquim, Figueiredo-Ribeiro, Hayashi, and Carvalho (2014) showed the presence of long chain inulin-type fructans in the underground organs of all four Asteracean geophyte species studied (Baccharis subdentata, Chresta curumbensis, Lessingianthus floccosus and Strophopappus glomeratus). Surprisingly, fructans are absent in native Cerrado tropical grass species (C4 grasses), thus showing a very distinct carbohydrate profile as compared to most temperate grasses (Moraes, Chatterton, Harrison, Filgueiras, \& Figueiredo-Ribeiro, 2012). These results fall in line with Hendry (1993), who indicated the absence of fructans in tropical 
plants. Moraes, Carvalho, Franco, Pollock, and Figueiredo-Ribeiro (2016), however, concluded an adaptive role for fructans in native Cerrado dicot plants in order to survive frequent disturbances (drought, fires, and low temperatures), allowing a fast recovery of the ground-layer vegetation.

Although fructans are found in crassulacean acid metabolism plants (Wang \& Nobel, 1998), until now fructan biosynthesis in C4 grasses is unknown. Exceptionally, C4 plants may be less drought resistant than closely related C3 plants (Ripley, Frole, \& Gilbert, 2010), but in general C4 metabolism represents an adaptive strategy for the plant against drought exposure, making the biosynthesis of fructans potentially redundant as a drought-protective mechanism. In a similar way the production of RFOs may be an example of carbohydrate redundancy, as both fructans and RFOs may have very similar functions (ElSayed, Rafudeen, \& Golldack, 2013; Van den Ende, 2013). There may be more extensive carbohydrate redundancy in microbial biofilms though as compared to the plant context, although this has not yet been subject to intense research. However, such views may help explain why a correlation between fructan production and stress exposure is more apparent for plants than for microbes. Nevertheless, Van den Ende et al. (2016) recently suggested that inulins and RFOs are nonredundant in B. sempervirens, where both types of carbohydrates are separated in time and perform different functions. It was proposed that RFOs function during cold acclimation in winter, whereas fructan synthesis (lower energetic cost) in early spring creates the necessary sink strength for growth.

\section{3 | Plant fructan structure-function relationships}

Lasseur et al. (2011) investigated the production of fructans in $L$. perenne with a focus on the characterization of the 6-SFT enzyme and discovered an intriguing mechanism in fructan structure-function relationship. Although this plant produces graminans, they described the sole production of neo-type fructans in the presence of 6G-FFT, as bifurcose production (and further graminan synthesis) ceased. Thus it seems that the neo-type fructans suppress the production of the other fructan type in this species. Intriguingly, although neo-type fructans are absent in Hordeum vulgare (Poaceae), the authors showed the production of 6G,6-kestotetraose in vivo when the 6-SFT from $\mathrm{H}$. vulgare was complemented with a L. perenne 6G-FFT. The 6-SFTs from both species share almost identical catalytic properties, so it was concluded that the differential production of neo-type fructans or graminans depends on the presence/absence of a 6G-FFT. Graminan production is repressed because the 6G-FFT has a higher affinity for the substrate 1-kestotriose. It can be hypothesized that these neo-type fructans provide an advantage over graminans for the growth and survival of this plant species. Nevertheless, this manuscript clearly indicates that our knowledge on the mechanisms behind the different fructan structures is very limited.

Why is a specific fructan type found in one species, but a different type is produced in others? There may be no clear reason at all, but on the other hand this may be linked to the survival under differing environmental circumstances due to specific physical and biochemical properties of each fructan type. With the current advances and tools in modern science this could be investigated in much more depth. With the genomic sequence of some fructan-producing plant species known, all potential GH32 family enzymes can be predicted based on the sequences of known fructan-metabolic enzymes. Using CRISPRCas9 technology, a GH32 gene can be knocked out in an elegant way (in case of two predicted $\mathrm{GH} 32$ isogenes this would require a knock-out mutant of each individual gene as well as a simultaneous knock-out; Bortesi \& Fischer, 2015; Puchta, 2017). The obtained mutants can give us more information on the importance of the fructan type in the plant's growth and survival.

Our knowledge on structure-function relationships in plant GH32 members has greatly increased (De Sadeleer, Vergauwen, Struyf, Le Roy, \& Van den Ende, 2015; Ritsema et al., 2006; Ritsema, Verhaar, Vijn, \& Smeekens, 2004 and references therein). This knowledge can now be exploited for gene editing with CRISPR-Cas9 technologies. For instance, only a few mutations are sufficient to transform a vacuolar invertase into a 1-SST (Schroeven, Lammens, Van Laere, \& Van den Ende, 2008). It was suggested that banana vacuolar invertases are already evolving into FTs (Cruz-Cárdenas et al., 2015). This study shows the potential to further increase FT activities and fructan contents in weak fructan accumulators such as banana. Moreover, by introducing new $\mathrm{GH} 32$ family genes, the possibility for the biosynthesis of other fructan types can be tested, as well as the potential impact on the plant's homeostasis and interaction with the environment. The suppression of graminan biosynthesis in L. perenne shows us that such mechanisms exist, although the underlying reasons are not yet understood.

\section{5 | THE FRUCTAN SYNDROME: A STORY OF WATER?}

The hygroscopic properties of fructans were suggested in a manuscript by Imam and Abd-Allah (1974), as mentioned above. The germination and growth of some economically important plant species increased in the soils supplemented with the fructan, although the exact reason is unclear. Apart from an effect on soil aggregation (Ashraf, Hasnain, \& Berge, 2006; Bezzate et al., 2000), a prebiotic effect on soil microbes or an immediate priming effect on the plant could boost the immune system. In this respect, soil-applied fructans may be partially degraded by soil microbes to produce smaller fructans with a potential stronger priming effect (Versluys et al., 2017). Inulin is known to be more hygroscopic as compared to small sugars, such as glucose, and dependent on the DP (Blakeney, McCleary, \& Mugford, 1997; Harada, Suzuki, Taniguchi, \& Sasaki, 1993). Generally, it is believed that the solubility in water is less for inulin-type fructans as compared to levans, however, a good comparison of physicochemical properties of inulins and levans (same or very similar DP and branching degree) is still absent in the literature (French, 1989; Phelps, 1965). These differences may help to shed some light on the issue highlighted by Lasseur et al. (2011) to understand why different fructan types are found in different species.

As a strong correlation between fructan accumulation in plants and survival in more extreme conditions becomes apparent, this can boost research in order to identify new fructan accumulators and fructan types. Aloe barbadensis Miller (Aloe vera, Asphodelaceae) is 


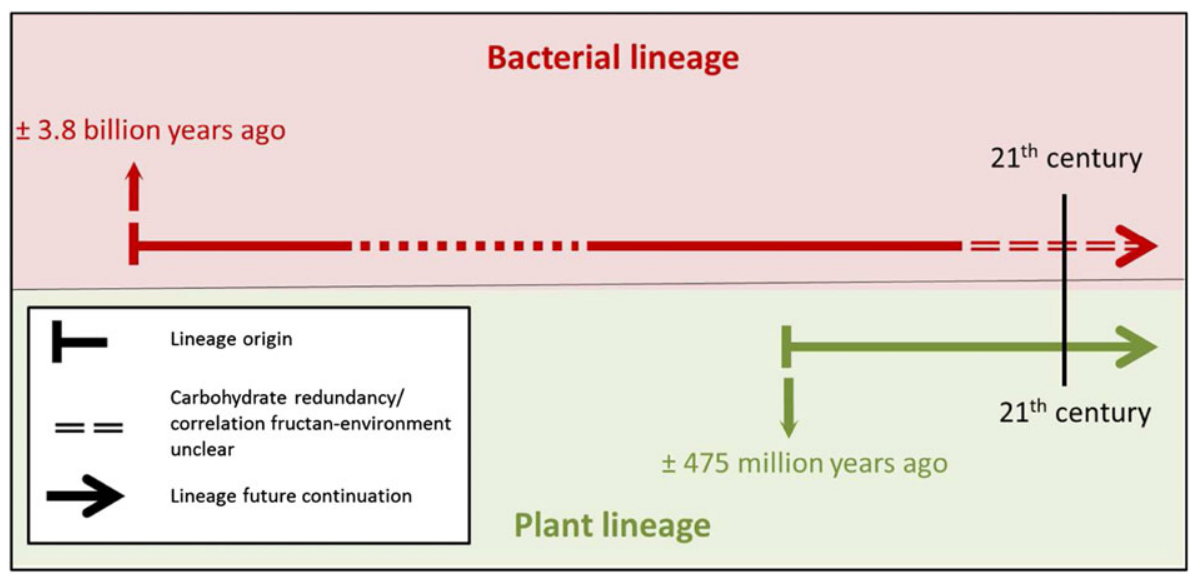

FIGURE 2 Evolutionary lineage of bacteria and plants. The evolutionary lineages of bacteria and plants are depicted in terms of fructan production. Although the bacterial lineage is very old (approx. 3.8 billion years), the plant lineage is much younger. Therefore, it is possible that plants are at a different time point in fructan evolution where fructan production is a recent adaptation to environmental stresses. On the other hand, fructan synthesis in bacteria may have evolved long ago as an adaptation to the environment. However, at this point the strong correlation between fructan production and environmental factors could be lost as other exopolysaccharides with similar functions replace fructans (carbohydrate functional redundancy)

often cultivated in semiarid conditions because of its high tolerance to water restriction. In general, the use of a crassulacean acid metabolism allows this species to tolerate water deficit. Nevertheless, a recent study showed the presence of several fructan types in succulent leaves of this species. Salinas, Handford, Pauly, Dupree, and Cardemil (2016) measured an increase in DP after more extreme drought. During water deficit, the predominant fructans (inulins, neo-inulins, and neo-levans) decreased, whereas more branched structures were synthesized.

Taken all together, there is accumulating evidence that Hendry (1993) was right when stating that water availability is an important determining factor to explain fructan distribution and fructan type and DP dynamics among and within plants. So, is the fructan syndrome in fact a "story of water" in plants? If true, could it also be a prominent factor in microbes as well? Although drought tolerance is of course clearly a problem of low-water availability, the same is true for freezing stress because it also lowers water availability. Water needs to be in its soluble form as a necessary solvent for all biochemical reactions. Interestingly, a strong correlation has recently been observed between sugar levels or hexokinase activity and the expression of PIP aquaporins, clearly indicating a role for the water soluble sugar status in water availability in the plant (Kelly et al., 2017). Although the latter paper did not focus on fructans as water soluble sugars, it raises the pertinent overall question through which direct (fructans having water attracting properties, membrane stabilization, and biofilm formation) or indirect (fructan signalling boosting stress tolerance pathways) mechanisms fructans could play a role, particularly in those organisms that are prone to at least some form of water scarcity, either on a temporal (e.g., plants) or a more persistent (e.g., microbial extremophiles) basis.

\section{6 | CONCLUSIONS}

Contrary to plants, studies investigating fructan producing microbes in extreme environments are still scarce and potential functional redundancy by other EPSs can impede this research. Proof of a clear link with survival in extreme environmental conditions remains largely absent. More hard evidence is required to be able to draw general conclusions. We hypothesize that these differences between microbes and plants concerning a correlation with biogeographical distribution and resistance to environmental stress may be the cause of different evolutionary timescales (Figure 2). In comparison to the microbial lineage (first appearance estimated at least 3.8 billion years ago; DeLong \& Pace, 2001), plants have a much more recent evolutionary lineage (approx. 475 million years ago; Wellman, Osterloff, \& Mohiuddin, 2003). Therefore, it could be that within the microbial lineage the period of close correlation between fructan production and adaptation to environmental factors has already past. Since then, on multiple occasions, other EPSs may have taken over the function of microbial fructans due to mutations in FT genes involved (carbohydrate redundancy). On the other hand, in the plant lineage, we may be at the point where fructans are only a "recent" (inducible) adaptation to withstand unfavorable conditions.

Why fructans are only produced in a limited number of microbes and plants remains still unknown, although likely other biomolecules can also offer solid solutions for similar environmental problems, both in microbes and plants. The link between fructans with exposure to and survival of adverse environmental conditions, especially water shortage, provides one possible attractive explanation, but more research is still needed in this area. Hopefully, this review will boost future applicative research in the microbe and plant areas (Toksoy Öner et al., 2016; Versluys et al., 2017).

Despite possible differences between plant and bacterial fructan functions, we highlight the following common themes and future research perspectives:

1. The integration of both microbial and plant worlds in this review is a novel approach, and the elements described allow us to get a more profound understanding on how fructan production in plants and microbes may be linked to adaptation to certain 
environmental conditions, especially those related to continuous or temporal water shortage.

2. In its broadest sense, all fructans are produced by "GH-J FTs" that are structurally and mechanistically similar in plants and microbes leading to the same linkage types but with different DPs and structural variations in plants as compared to microbes. Although there is good progress on understanding structure-function relationships in plant and microbial FTs, the overall structurefunction picture for fructans themselves remains largely unclear.

3. Both in plants and microbes, fructan synthesis releases glucose that can be used for growth whereas the fructans seem to be often involved in stress tolerance, especially in relation to water shortage. In plants, the fructan syndrome is induced under stress or during natural drying processes such as during cereal grain development. In microbes, they are often constitutively secreted as EPS protecting against environmental conditions and involved in adhesion mechanisms such as biofilm formation. Nonetheless, fructans may have a common protective function because of their physicochemical properties (such as membrane interaction and flexibility), which is particularly important under water shortage.

4. Both in plants and microbes, fructans may also be used as a storage carbohydrate and their degradation products may be used to fuel growth (ATP production or C source).

5. During the process of microbial or plant fructan degradation, degradation products may have a secondary function as signalling molecules in both systems. In particular, these signalling molecules could be crucial during pathogenic and symbiotic plant-microbe interactions, but these ideas are still very hypothetical and require much further research.

6. The recruitment of a GH-J type FT in phages suggests that these organisms may influence both bacterial and plant fructan dynamics and perhaps in particular with the small, diffusable signal molecules that arise from fructan hydrolysis involved in the interaction between plants and microbes. This represents a challenging area for future research.

\section{ACKNOWLEDGMENTS}

W. V. d. E. and M. V. are supported by funds from FWO Vlaanderen. O. K. and E. T. O. acknowledge the financial support provided by TUBITAK (project 1150495) by Marmara University Research Foundation (project FEN-D-100616-0301).

\section{ORCID}

Wim Van den Ende (10 http://orcid.org/0000-0003-1137-3614

\section{REFERENCES}

AbdElgawad, H., Peshev, D., Zinta, G., Van den Ende, W., Janssens, I. A., \& Asard, H. (2014). Climate extreme effects on the chemical composition of temperate grassland species under ambient and elevated $\mathrm{CO}_{2}$ : A comparison of fructan and non-fructan accumulators. PLoS ONE, 9(3). e92044

Abeynayake, S. W., Etzerodt, T. P., Jonaviciené, K., Byrne, S., Asp, T., \& Boelt, B. (2015). Fructan metabolism and changes in fructan composition during cold acclimation in perennial ryegrass. Frontiers in Plant Science, 6, 329.
Albrecht, G., \& Biemelt, S. (1998). A comparative study on carbohydrate reserves and ethanolic fermentation in the roots of two wetland and non-wetland species after commencement of hypoxia. Physiologia Plantarum, 104, 81-86.

Albrecht, G., Biemelt, S., \& Baumgartner, S. (1997). Accumulation of fructans following oxygen deficiency stress in related plant species with different flooding tolerances. New Phytologist, 136, 137-144.

Ammar, Y. B., Matsubara, T., Ito, K., lizuka, M., Limpaseni, T., Pongsawasdi, P., \& Minamiura, N. (2002). Characterization of a thermostable levansucrase from Bacillus sp. TH4-2 capable of producing high molecular weight levan at high temperature. Journal of Biotechnology, 99(2), 111-119.

Antošová, M., \& Polakovič, M. (2001). Fructosyltransferases: The enzymes catalyzing production of fructooligosaccharides. Chemical Papers, 55(6), 350-358.

Anwar, M. A., Kralj, S., van der Maarel, M. J., \& Dijkhuizen, L. (2008). The probiotic Lactobacillus johnsonii NCC 533 produces high-molecularmass inulin from sucrose by using an inulosucrase enzyme. Applied and Environmental Microbiology, 74(11), 3426-3433.

Arbillot, J., Gonzalez, B., Fontaine, O., \& Boucaud, J. (2009). Effect of temperature on fructan exohydrolase activity in leaves of Lolium perenne (L.). Food Hydrocolloids, 5, 215-217.

Asega, A. F., Nascimento, J. R. O., \& Carvalho, M. A. M. (2011). Increased expression of fructan 1-exohydrolase in rhizophores of Vernonia herbaceae during sprouting and exposure to low temperature. Journal of Plant Physiology, 168, 558-565.

Ashraf, M., Hasnain, S., \& Berge, O. (2006). Bacterial exo-polysaccharides and productivity of the salt affected soils II: Effect of exo-polysaccharides (EPS) producing bacterial inoculation on growth of roots of wheat (Triticum aestivum L.) plants grown in a salt-affected soil. International Journal of Environmental Science \& Technology, 3(41), 45-53.

Babu, P., Chandel, A. K., \& Singh, O. V. (2015). Survival mechanisms of extremophiles. In Extremophiles and their applications in medical processes (pp. 9-23). Cham, Switzerland: Springer International Publishing.

Banguela, A., Trujillo, L. E., Arrieta, J. G., Rodríguez, R., Pérez, E., Menéndez, C., ... Hernández, L. (2012). Producción de levana bacteriana altamente polimerizada en dos hospederos eucariontes de interés biotecnológico. Biotecnología Aplicada, 29(2), 122-126.

Belghith, K. S., Dahech, I., Belghith, H., \& Mejdoub, H. (2012). Microbial production of levansucrase for synthesis of fructooligosaccharides and levan. International Journal of Biological Macromolecules, 50(2), 451-458.

Benigar, E., Dogsa, I., Stopar, D., Jamnik, A., Cigić, I. K., \& Tomšič, M. (2014). Structure and dynamics of a polysaccharide matrix: Aqueous solutions of bacterial levan. Langmuir, 30(14), 4172-4182.

Bezzate, S., Aymerich, S., Chambert, R., Czarnes, S., Berge, O., \& Heulin, T. (2000). Disruption of the Paenibacillus polymyxa levansucrase gene impairs its ability to aggregate soil in the wheat rhizosphere. Environmental Microbiology, 2(3), 333-342.

Blakeney, A. B., McCleary, B. V., \& Mugford, D. C. (1997). Fructans-Analytical approaches to a fiber that ferments. Chemistry in Australia, 17-19.

Blanch, M., Dolores Alvarez, M., Sanchez-Ballesta, M. T., Escribano, M. I., \& Merodio, C. (2017). Water relations, short-chain oligosaccharides and rheological properties in lettuces subjected to limited water supply and low temperature stress. Scientia Horticulturae, 225, 726-735.

Bolouri Moghaddam, M. R., \& Van den Ende, W. (2012). Sugars and plant innate immunity. Journal of Experimental Botany, 63, 3989-3998.

Bonnett, G. D., Sims, I. M., Simpson, R. J., \& Cairns, A. J. (1997). Structural diversity of fructan in relation to the taxonomy of the Poaceae. New Phytologist, 136, 11-17.

Bortesi, L., \& Fischer, R. (2015). The CRISPR/Cas9 system for plant genome editing and beyond. Biotechnology Advances, 33, 41-52.

Bouchenak-Khelladi, Y., Verboom, G. A., Savolainen, V., \& Hodkinson, T. R. (2010). Biogeography of the grasses (Poaceae): A phylogenetic 
approach to reveal evolutionary history in geographical space and geological time. Botanical Journal of the Linnean Society, 162, 543-557.

Bowen, W. H., \& Koo, H. (2011). Biology of Streptococcus mutans-derived glucosyltransferases: Role in extracellular matrix formation of cariogenic biofilms. Caries Research, 45, 69-86.

Cairns, A. J. (2003). Fructan biosynthesis in transgenic plants. Journal of Experimental Botany, 54(382), 549-567.

Caleffi, E. R., Krausová, G., Hyrslová, I., Paredes, L. L. R., dos Santos, M. M., Sassaki, G. L., ... de Oliveira, A. J. B. (2015). Isolation and prebiotic activity of inulin-type fructan extracted from Pfaffia glomerata (Sprenger) Pedersen roots. International Journal of Biological Macromolecules, 80, 392-399.

Carson, J. (2013). U.S. patent application No. 13/857,233.

Chang, W. S., van de Mortel, M., Nielsen, L., de Guzman, G. N., Li, X., \& Halverson, L. J. (2007). Alginate production by Pseudomonas putida creates a hydrated microenvironment and contributes to biofilm architecture and stress tolerance under water-limiting conditions. Journal of Bacteriology, 189(22), 8290-8299.

Cho, Y. H., \& Yoo, S. D. (2011). Signaling role of fructose mediated by FINS1/FBP in Arabidopsis thaliana. PLoS Genetics, 6. e1001263

Conrath, U. (2015). Priming for enhanced defense. Annual Reviews in Plant Pathology, 53, 97-119.

Côté, G. L., \& Skory, C. D. (2014). Effects of mutations at threonine-654 on the insoluble glucan synthesized by Leuconostoc mesenteroides NRRL B-1118 glucansucrase. Applied Microbiology and Biotechnology, 98(15), 6651-6658.

Cruz-Cárdenas, C. I., Miranda-Ham, M. L., Castro-Concha, L. A., Ku-Cauich, J. R., Vergauwen, R., Reijnders, T., ... Escobedo-GraciaMedrano, R. M. (2015). Fructans and other water soluble carbohydrates in vegetative organs and fruits of different Musa spp. accessions. Frontiers in Plant Science, 6, 395.

Cuskin, F., Flint, J. E., Gloster, T. M., Morland, C., Baslé, A., Henrissat, B., ... Gilbert, H. J. (2012). How nature can exploit nonspecific catalytic and carbohydrate binding modules to create enzymatic specificity. Proceedings of the National Academy of Sciences, 109(51), 20889-20894.

Daguer, J. P., Geissmann, T., Petit-Glatron, M. F., \& Chambert, R. (2004). Autogenous modulation of the Bacillus subtilis sacB-levB-yveA levansucrase operon by the levB transcript. Microbiology, 150(11), 3669-3679.

Dahech, I., Belghith, K. S., Belghith, H., \& Mejdoub, H. (2012). Partial purification of a Bacillus licheniformis levansucrase producing levan with antitumor activity. International Journal of Biological Macromolecules, 51(3), 329-335.

DasSarma, S., \& DasSarma, P. (2015). Halophiles and their enzymes: Negativity put to good use. Current Opinion in Microbiology, 25, 120-126.

De Coninck, B., Le Roy, K., Francis, I., Clerens, S., Vergauwen, R., Halliday, A. M., ... Van den Ende, W. (2005). Arabidopsis AtcwINV3 and 6 are not invertases but are fructan exohydrolases (FEHs) with different substrate specificities. Plant, Cell and Environment, 28, 432-443.

De Roover, J., Vandenbranden, K., Van Laere, A., \& Van den Ende, W. (2000). Drought induces fructan synthesis and 1-SST (sucrose: sucrose fructosyltransferase) in roots and leaves of chicory seedlings (Cichorium intybus L.). Planta, 210, 808-814.

De Sadeleer, E., Vergauwen, R., Struyf, T., Le Roy, K., \& Van den Ende, W. (2015). 1-FFT amino acids involved in high DP inulin accumulation in Viguiera discolor. Frontiers in Plant Science, 6, 616.

Del Viso, F., Casabuono, A. C., Couto, A. S., Hopp, H. E., Puebla, A. F., \& Heinz, R. A. (2011). Functional characterization of a sucrose:fructan 6fructosyltransferase of the cold-resistant grass Bromus pictus by heterologous expression in Pichia pastoris and Nicotiana tabacum and its involvement in freezing tolerance. Journal of Plant Physiology, 168, 493-499.

Del Viso, F., Puebla, A. F., \& Hopp, H. E. (2009). Cloning and functional characterization of a fructan 1-exohydrolase (1-FEH) in the cold tolerant Patagonian species Bromus pictus. Planta, 231, 13.
DeLong, E. F., \& Pace, N. R. (2001). Environmental diversity of bacteria and archaea. Systematic Biology, 50(4), 470-478.

Di Bartolomeo, F., \& Van den Ende, W. (2015). Fructose and fructans: Opposite effects on health? Plant Foods for Human Nutrition, 70, 227-237.

Dinakar, C., \& Bartels, D. (2013). Desiccation tolerance in resurrection plants: New insights from transcriptome, proteome and metabolome analysis. Frontiers in Plant Science, 4, 482.

Dogsa, I., Brloznik, M., Stopar, D., \& Mandic-Mulec, I. (2013). Exopolymer diversity and the role of levan in Bacillus subtilis biofilms. PLoS ONE, 8(4). e62044

Dolezal, J., Dvorsky, M., Kopecky, M., Liancourt, P., Hiiesalu, I., Macek, M., ... Schweingruber, F. (2016). Vegetation dynamics at the upper elevational limit of vascular plants in Himalaya. Science Reports, 6, 24881.

Dong, C., Zhang, L., Xu, R., Zhang, G., Zhou, Y., Han, X., ... Sun, Y. (2015). Structural characterization and immunostimulating activity of a levantype fructan from Curcuma kwangsiensis. International Journal of Biological Macromolecules, 77, 99-104.

Duran-Flores, D., \& Heil, M. (2016). Sources of specificity in plant damaged-self recognition. Current Opinion in Plant Biology, 32, 77-87.

EISayed, A. I., Rafudeen, M. S., \& Golldack, D. (2013). Physiological aspects of raffinose family oligosaccharides in plants: Protection against abiotic stress. Plant Biology, 16, 1-8.

Engelhardt, C., Petereit, F., Lechtenberg, M., Liefländer-Wulf, U., \& Hensel, A. (2016). Qualitative and quantitative phytochemical characterization of Myrothamnus flabellifolia Welw. Fitoterapia, 114, 69-80.

Finore, I., Lama, L., Poli, A., Di Donato, P., \& Nicolaus, B. (2015). Biotechnology implications of extremophiles as life pioneers and wellspring of valuable biomolecules. In Microbial factories (pp. 193-216). Bangalore, Mumbai, New Delhi: Springer India.

Flemming, H. C. (2011). The perfect slime. Colloids and Surfaces B: Biointerfaces, 86(2), 251-259.

Franco-Robles, E., \& López, M. G. (2015). Implication of fructans in health: Immunomodulatory and antioxidant mechanisms. The Scientific World Journal, 2015, 289267.

French, A. D. (1989). Chemical and physical properties of fructans. Journal of Plant Physiology, 134, 125-136.

Garcia, P. M. A., Asega, A. F., Silva, E. A., \& Carvalho, M. A. M. (2011). Effect of drought and re-watering on fructan metabolism in Vernonia herbaceae (Vell.) Rusby. Plant Physiology \& Biochemistry, 40, 664-670.

Gaudet, D. A., \& Laroche, A. (1997). Winter survival of cereals parasitized by snow mold. In H. Li, \& T. H. H. Chen (Eds.), Plant cold hardiness (pp. 331-342). Boston, MA: Springer.

Givnish, T. J., Zuluaga, A., Marques, I., Lam, V. K. Y., Gomez, M. S., Iles, W. J. D., ... Graham, W. (2016). Phylogenomics and historical biogeography of the monocot order Liliales: Out of Australia and through Antarctica. Cladistics, 32, 581-605.

Graziano, G., \& Merlino, A. (2014). Molecular bases of protein halotolerance. Biochimica et Biophysica Acta (BBA)-Proteins and Proteomics, 1844(4), 850-858.

Habibi, H., \& Khosravi-Darani, K. (2017). Effective variables on production and structure of xanthan gum and its food applications: A review. Biocatalysis and Agricultural Biotechnology, 10, 130-140.

Han, J., Xu, X., Gao, C., Liu, Z., \& Wu, Z. (2016). Levan-producing Leuconostoc citreum strain BD1707 and its growth in tomato juice supplemented with sucrose. Applied and Environmental Microbiology, 82(5), 1383-1390.

Han, Y. W. (1990). Microbial levan. Advances in Applied Microbiology, 35, 171-194.

Harada, T., Suzuki, S., Taniguchi, H., \& Sasaki, T. (1993). Characteristics and applications of a polyfructan synthesized from sucrose by Aspergillus sydowi conidia. In K. Nishinari, \& D. Etsushiro (Eds.), Food hydrocolloids -Structures, properties and functions (pp. 77-82). Boston, MA: Plenum Press. 
Hay, I. D., Rehman, Z. U., Moradali, M. F., Wang, Y., \& Rehm, B. H. (2013). Microbial alginate production, modification and its applications. Microbial Biotechnology, 6(6), 637-650.

Heil, M. (2009). Damaged-self recognition in plant herbivore defense. Trends in Plant Science, 14(7), 356-363.

Hendry, G. A. F. (1993). Evolutionary origins and natural functions of fructans-A climatological, biogeographic and mechanistic appraisal. New Phytologist, 123, 3-14.

Hendry, G. A. F., \& Wallace, R. K. (1993). The origin, distribution and evolutionary significance of fructans. In M. Suzuki, \& J. N. Chatterton (Eds.), Science and Technology of Fructans (pp. 120-141). Boca Raton, Florida: CRC Press.

Hincha, D. K., Livingston, D. P., Premakumar, R., Zuther, E., Obel, N., Cacela, C., \& Heyer, G. (2007). Fructans from oat and rye: Composition and effects on membrane stability during drying. Biochimica et Biophysica Acta, 1768, 1611-1619.

Hisano, H., Kanazawa, A., Kawakami, A., Yoshida, M., Shimamoto, Y., \& Yamada, T. (2004). Transgenic perennial ryegrass plants expressing wheat fructosyltransferases genes accumulate increased amounts of fructan and acquire increased tolerance on a cellular level to freezing. Plant Science, 167, 861-868.

Imam, G. M., \& Abd-Allah, N. M. (1974). Fructosan, a new soil conditioning polysaccharide isolated from the metabolites of Bacillus polyxyma AS-1 and its clinical applications. Egyptian Journal of Botany, 17, 19-26.

Inthanavong, L., Tian, F., Khodadadi, M., \& Karboune, S. (2013). Properties of Geobacillus stearothermophilus levansucrase as potential biocatalyst for the synthesis of levan and fructooligosaccharides. Biotechnology Progress, 29(6), 1405-1415.

Iriki, N., Nishio, Z., Kawakami, A., Yoshida, M., Kuroki, M., Funtov, K., \& Kawahara, T. (2005). Fructan content in Aegilops cylindrical and its relationship to snow mold resistance and freezing tolerance. Plant Production Science, 8(5), 563-566.

Ishigura, Y., Ueno, K., Onodera, S., Benkeblia, N., \& Shiomi, N. (2011). Effect of temperatures on inulobiose and inulooligosaccharides in burdock roots during storage. Journal of Food Composition \& Analysis, 24, 398-401.

Jarzyniak, K. M., \& Jasiński, M. (2014). Membrane transporters and drought resistance-A complex issue. Frontiers in Plant Science, 5, 687.

Jensen, K. B., Harrison, P., Chatterton, N. J., Bushman, B. S., \& Creech, J. E. (2013). Seasonal trends in nonstructural carbohydrates in cool- and warm-season grasses. Crop Science, 54(5), 2328-2340.

Jiang, Y., Watkins, E., Liu, S., Yu, X., \& Luo, N. (2010). Antioxidative responses and candidate gene expression in prairie junegrass under drought stress. Journal of the American Society for Horticultural Science, 135(4), 303-309.

Karan, R., Kumar, S., Sinha, R., \& Khare, S. K. (2012). Halophilic microorganisms as sources of novel enzymes. In T. Satyanarayana, et al. (Eds.), Microorganisms in sustainable agriculture and biotechnology (pp. 555-579). Dordrecht: Springer Netherlands.

Kawakami, A., Sato, Y., \& Yoshida, M. (2008). Genetic engineering of rice capable of synthesizing fructans and enhancing chilling tolerance. Journal of Experimental Botany, 59(4), 793-802.

Kawakami, A., \& Yoshida, M. (2012). Graminan breakdown by fructan exohydrolase induced in winter wheat inoculated with snow mold. Journal of Plant Physiology, 169, 294-302.

Kazak Sarilmiser, H., Ates, O., Ozdemir, G., Arga, K. Y., \& Toksoy Öner, E. (2015). Effective stimulating factors for microbial levan production by Halomonas smyrnensis AAD6T. Journal of Bioscience and Bioengineering, 119(4), 455-463.

Kekez, B. D., Gojgic-Cvijovic, G. D., Jakovljevic, D. M., Kojic, J. S., Markovic, M. D., Beskoski, V. P., \& Vrvic, M. M. (2015). High levan production by Bacillus licheniformis NSO32 using ammonium chloride as the sole nitrogen source. Applied Biochemistry and Biotechnology, 175(6), 3068-3083.

Kelly, G., Sade, N., Doron-Faigenboim, A., Lemer, S., Shatil-Cohen, A., Yeselson, Y., ... Granot, D. (2017). Sugar and hexokinase suppress expression of PIP aquaporins and reduce leaf hydraulics that preserves leaf water potential. The Plant Journal, 91(2), 325-339.

Keunen, E., Peshev, D., Vangronsveld, J., Van den Ende, W., \& Cuypers, A. (2013). Plant sugars are crucial players in the oxidative challenge during abiotic stress: Extending the traditional concept. Plant, Cell and Environment, 36, 1242-1255.

Koczan, J. M., McGrath, M. J., Zhao, Y., \& Sundin, G. W. (2009). Contribution of Erwinia amylovora exopolysaccharides amylovoran and levan to biofilm formation: Implications in pathogenicity. Phytopathology, 99(11), 1237-1244.

Koshland, D. E., \& Stein, S. S. (1954). Correlation of bond breaking with enzyme specificity. Cleavage point of invertase. Journal of Biological Chemistry, 208(1), 139-148.

Kralj, S., van Geel-Schutten, I. G., Faber, E. J., van der Maarel, M. J., \& Dijkhuizen, L. (2005). Rational transformation of Lactobacillus reuteri 121 reuteransucrase into a dextransucrase. Biochemistry, 44(25), 9206-9216.

Krzyściak, W., Jurczak, A., Kościelniak, D., Bystrowska, B., \& Skalniak, A. (2014). The virulence of Streptococcus mutans and the ability to form biofilms. European Journal of Clinical Microbiology \& Infectious Diseases, 33(4), 499-515.

Lammens, W., Le Roy, K., Schroeven, L., Van Laere, A., Rabijns, A., \& Van den Ende, W. (2009). Structural insights into glycoside hydrolase family 32 and 68 enzymes: Functional implications. Journal of Experimental Botany, 60, 727-740.

Lammens, W., Le Roy, K., Yuan, S., Vergauwen, R., Rabijns, A., Van Laere, A., ... Van den Ende, W. (2012). Crystal structure of a 6-SST/6-SFT from Pachysandra terminalis, a plant fructan biosynthesizing enzyme in complex with its acceptor substrate 6-kestose. The Plant Journal, 70, 205-219.

Lasseur, B., Lothier, J., Djoumad, A., De Coninck, B., Smeekens, S., Van Laere, A., ... Prud'homme, M. (2006). Molecular and functional characterization of a cDNA encoding fructan:fructan 6G-fructosyltransferase (6G-FFT)/fructan:fructan 1-fructosyltransferase (1-FFT) from perennial ryegrass (Lolium perenne L.). Journal of Experimental Botany, 57(11), 2719-2734.

Lasseur, B., Lothier, J., Morvan-Bertrand, A., Escobar-Guttiérez, A., Humphreys, M. O., \& Prud'homme, M. (2007). Impact of defoliation frequency on regrowth and carbohydrate metabolism in constrasting varieties of Lolium perenne. Functional Plant Biology, 34, 418-430.

Lasseur, B., Lothier, J., Wiemken, A., Van Laere, A., Morvan-bertrand, A., Van den Ende, W., \& Prud'homme, M. (2011). Towards a better understanding of the generation of fructan structure diversity in plants: Molecular and functional characterization of a sucrose:fructan 6fructosyltransferase (6-SFT) cDNA from perennial ryegrass (Lolium perenne). Journal of Experimental Botany, 62(6), 1871-1885.

Laue, H., Schenk, A., Li, H., Lambertsen, L., Neu, T. R., Molin, S., \& Ullrich, M. S. (2006). Contribution of alginate and levan production to biofilm formation by Pseudomonas syringae. Microbiology, 152(10), 2909-2918.

Le Roy, K., Lammens, W., Van Laere, A., \& Van den Ende, W. (2008). Influencing the binding configuration of sucrose in the active sites of chicory fructan 1-exohydrolase and sugar beet fructan 6-exohydrolase. New Phytologist, 178, 572-580.

Le Roy, K., Vergauwen, R., Struyf, T., Yuan, S., Lammens, W., Mátrai, J., ... Van den Ende, W. (2013). Understanding the role of defective invertases in plants: Tobacco Nin88 fails to degrade sucrose. Plant Physiology, 161(4), 1670-1681.

Leemhuis, H., Pijning, T., Dobruchowska, J. M., van Leeuwen, S. S., Kralj, S., Dijkstra, B. W., \& Dijkhuizen, L. (2013). Glucansucrases: Three-dimensional structures, reactions, mechanism, a-glucan analysis and their implications in biotechnology and food applications. Journal of Biotechnology, 163(2), 250-272.

Leloup, L., Petit-Glatron, M. F., Chambert, R., \& Le Saux, J. (1999). Kinetics of the secretion of Bacillus subtilis levanase overproduced during the exponential phase of growth. Microbiology, 145(3), 613-619. 
Lewis, D. L. (1993). Nomenclature and diagrammatic representation of oligomeric fructans-A paper for discussion. New Phytologist, 124, 583-594.

Li, H., Yang, A., Zhang, X., Gao, F., \& Zhang, J. (2007). Improving freezing tolerance of transgenic tobacco expressing sucrose:sucrose 1fructosyltransferase gene from Lactuca sativa. Plant Cell, Tissue \& Organ Culture, 89, 37-48.

Li, P., Wind, J. J., Shi, X., Zhang, H., Hanson, J., Smeekens, S. C., \& Teng, S. (2011). Fructose sensitivity is suppressed in Arabidopsis by the transcription factor NAC089 lacking the membrane-bound domain. Proceedings of the National Academies of Sciences U.S.A., 108, 3436-3441.

Li, W., Yu, S., Zhang, T., Jiang, B., \& Mu, W. (2015). Recent novel applications of levansucrases. Applied Microbiology and Biotechnology, 99(17), 6959-6969.

Lindeberg, G. (1957). Levan-forming halophilic bacteria. Nature, 4595, 1141.

Livingston, D. P., \& Henson, C. A. (1998). Apoplastic sugars, fructans, fructan exohydrolase, and invertase in winter oat: Responses to second-phase cold hardening. Plant Physiology, 116, 403-408.

Livingston, D. P., Hincha, D. K., \& Heyer, G. (2009). Fructan and its relationship to abiotic stress tolerance in plants. Cellular \& Molecular Life Sciences, 66, 2007-2023.

Livingston, D. P., Knievel, D. P., \& Gildow, F. (1994). Fructan synthesis in oat: Oligomer accumulation in stems during cold hardening and their in vitro synthesis in a crude enzyme extract. New Phytologist, 127, 27-36.

López, M. G., Mancilla-Margalli, N. A., \& Mendoza-Diaz, G. (2003). Moleculer structures of fructans from Agave tequilana Weber var. azul. Journal of Agricultural \& Food Chemistry, 51, 7835-7840.

López-Velázquez, G., Parra-Ortiz, M., De la Mora-De la Mora, I., GarcíaTorres, I., Enríquez-Flores, S., Alcántara-Ortigoza, M. A., ... GutiérrezCastrellón, P. (2015). Effects of fructans from Mexican Agave in newborns fed with infant formula: A randomized controlled trial. Nutrients, 7, 8939-8951.

Lothier, J., Van Laere, A., Prud'homme, M., Van den Ende, W., \& MorvanBertrand, A. (2014). Cloning and characterization of a novel fructan 6exohydrolase strongly inhibited by sucrose in Lolium perenne. Planta, $240,629-643$

Maaroufi, H., \& Levesque, R. C. (2015). Glycoside hydrolase family 32 is present in Bacillus subtilis phages. Virology Journal, 12(1), 157.

Madern, D., Ebel, C., \& Zaccai, G. (2000). Halophilic adaptation of enzymes. Extremophiles, 4(2), 91-98.

Magnússon, H., \& Möller, A. (1985). Ropiness in the brine of sugar-salted herring. International Journal of Food Microbiology, 1(5), 253-261.

Maina, N. H., Tenkanen, M., Maaheimo, H., Juvonen, R., \& Virkki, L. (2008). NMR spectroscopic analysis of exopolysaccharides produced by Leuconostoc citreum and Weissella confusa. Carbohydrate Research, 343(9), 1445-1455.

Malang, S. K., Maina, N. H., Schwab, C., Tenkanen, M., \& Lacroix, C. (2015). Characterization of exopolysaccharide and ropy capsular polysaccharide formation by Weissella. Food Microbiology, 46, 418-427.

Maleux, K., \& Van den Ende, W. (2007). Levans in excised leaves of Dactylis glomerata: Effects of light, sugars, temperature and senescence. Journal of Plant Biology, 50(6), 671-680.

Mancilla-Margalli, N. A., \& Lopez, M. G. (2006). Water-soluble carbohydrates and fructan structure patterns from Agave and Dasylirion species. Journal of Agricultural \& Food Chemistry, 54, 7832-7839.

Mardo, K., Visnapuu, T., Vija, H., Aasamets, A., Viigand, K., \& Alamäe, T. (2017). A highly active endo-levanase BT1760 of a dominant mammalian gut commensal Bacteroides thetaiotaomicron cleaves not only various bacterial levans, but also levan of timothy grass. PLoS One, 12(1). e0169989
Martinez-Medina, A., Flors, V., Heil, M., Mauch-Mani, B., Pieterse, C. M. J., Pozo, M. J., ... Conrath, U. (2016). Recognizing plant defense priming. Trends in Plant Science, 21(10), 818-822.

Matros, A., Peshev, D., Peukert, M., Mock, H. P., \& Van den Ende, W. (2015). Sugars as hydroxyl radical scavengers: Proof-of-concept by studying the fate of sucralose in Arabidopsis. The Plant Journal, 82, 822-839.

Matsuhira, H., Tamura, K., Tamagake, H., Sato, Y., Anzai, H., \& Yoshida, M. (2014). High production of plant type levan in sugar beet transformed with timothy (Phleum pratense) 6-SFT genes. Journal of Biotechnology, 192, 215-222.

Meguro-Maoka, A., \& Yoshida, M. (2016). Analysis of seasonal expression levels of wheat fructan exohydrolase (FEH) genes regulating fructan metabolism involved in wintering ability. Journal of Plant Physiology, 191, 54-62.

Mehrotra, R., Bhalothia, P., Bansal, P., Basantani, M. K., Bharti, V., \& Mehrotra, S. (2014). Abscisic acid and abiotic stress tolerance-Different tiers of regulation. Journal of Plant Physiology, 171, 486-496.

Méndez-Lorenzo, L., Porras-Domínguez, J. R., Raga-Carbajal, E., Olvera, C., Rodríguez-Alegría, M. E., Carrillo-Nava, E., ... Munguía, A. L. (2015). Intrinsic levanase activity of Bacillus subtilis 168 levansucrase (SacB). PLoS One, 10(11). e0143394

Mensink, M. A., Frijlink, H. W., Maarschalk, K. V., \& Hinrichs, W. L. J. (2015a). Inulin, a flexible oligosaccharide II: Review of its physicochemical characteristics. Carbohydrate Polymers, 130, 405-419.

Mensink, M. A., Frijlink, H. W., Maarschalk, K. V., \& Hinrichs, W. L. J. (2015b). Inulin, a flexible oligosaccharide II: Review of its pharmaceutical applications. Carbohydrate Polymers, 134, 418-428.

Miasnikov, A. N. (1997). Characterization of a novel endo-levanase and its gene from Bacillus sp. L7. FEMS Microbiology Letters, 154(1), 23-28.

Moore, J. P., Lindsey, G. G., Farrant, J. M., \& Brandt, W. F. (2007). An overview of the biology of the dessication-tolerant resurrection plant Myrothamnus flabellifolia. Annals of Botany, 99, 211-217.

Moraes, M. G., Carvalho, M. A. M., Franco, A. C., Pollock, C. J., \& Figueiredo-Ribeiro, R. C. L. (2016). Fire and drought: Soluble carbohydrate storage and survival mechanisms in herbaceous plants from the Cerrado. BioScience, 66, 107-117.

Moraes, M. G., Chatterton, N. J., Harrison, P. A., Filgueiras, T. S., \& Figueiredo-Ribeiro, R. C. L. (2012). Diversity of non-structural carbohydrates in grasses (Poaceae) from Brazil. Grass \& Forage Science, 68, 165-177.

Moreno-Vilet, L., Garcia-Hernandez, M. H., Delgado-Portales, R. E., CorralFernandez, N. E., Cortez-Espinosa, N., Ruiz-Cabrera, M. A., \& PortalesPerez, D. P. (2014). In vitro assessment of agave fructans (Agave salmiana) as prebiotics and immune system activators. International Journal of Biological Macromolecules, 63, 181-187.

Muguerza, M., Gondo, T., Yoshida, M., Kawakami, A., Terami, F., Yamada, T., \& Akashi, R. (2013). Modification of the total soluble sugar content of the C4 grass Paspalum notatum expressing the wheat-derived sucrose: sucrose 1-fructosyltransferase and sucrose:fructan 6fructosyltransferase genes. Grassland Science, 59, 196-204.

Nagasawa, R., Sato, T., \& Senpuku, H. (2017). Raffinose induces biofilm formation by Streptococcus mutans in low concentrations of sucrose by increasing production of extracellular DNA and fructan. Applied and Environmental Microbiology, AEM-00869-17.

Nakapong, S., Pichyangkura, R., Ito, K., lizuka, M., \& Pongsawasdi, P. (2013). High expression level of levansucrase from Bacillus licheniformis RN-01 and synthesis of levan nanoparticles. International Journal of Biological Macromolecules, 54, 30-36.

Nasir, D. Q., Wahyuningrum, D., \& Hertadi, R. (2015). Screening and characterization of levan secreted by halophilic bacterium of Halomonas and Chromohalobacter genuses originated from Bledug Kuwu mud crater. Procedia Chemistry, 16, 272-278.

Oliveira, V. F., Silva, E. A., \& Carvalho, M. A. M. (2016). Elevated $\mathrm{CO}_{2}$ atmosphere minimizes the effect of drought on the Cerrado species Chrysolaena obovate. Frontiers in Plant Science, 7, 810. 
Oliveira, V. F., Silva, E. A., Zaidan, L. B. P., \& Carvalho, M. A. M. D. (2013). Effects of elevated $\mathrm{CO}_{2}$ concentration and water deficit on fructan metabolism in Viguiera discolor Baker. Plant Biology, 15, 471-482.

Oliveira-Joaquim, E. D., Figueiredo-Ribeiro, R. D. C. L., Hayashi, A. H., \& Carvalho, M. A. M. D. (2014). Inulin contents and tissue distribution in underground storage organs of Asteraceae species from the Brazilian rocky fields. Botany, 92(11), 827-836.

Oren, A. (2013). Life at high salt concentrations, intracellular $\mathrm{KCl}$ concentrations, and acidic proteomes. Frontiers in Microbiology, 4, 315.

Orthen, B., \& Wehrmeyer, A. (2004). Seasonal dynamics of non-structural carbohydrates in bulbs and shoots of the geophyte Galanthus nivalis. Physiologia Plantarum, 120, 529-536.

Ortiz-Soto, M. E., Possiel, C., Görl, J., Vogel, A., Schmiedel, R., \& Seibel, J. (2017). Impaired coordination of nucleophile and increased hydrophobicity in the +1 subsite shift levansucrase activity towards transfructosylation. Glycobiology, 27(8), 755-765.

Ortiz-Soto, M. E., Rivera, M., Rudiño-Piñera, E., Olvera, C., \& LópezMunguía, A. (2008). Selected mutations in Bacillus subtilis levansucrase semi-conserved regions affecting its biochemical properties. Protein Engineering Design and Selection, 21(10), 589-595.

Özcan, E., \& Toksoy Öner, E. (2015). Microbial production of extracellular polysaccharides from biomass sources. In K. G. Ramawat, \& J. M. Mérillon (Eds.), Polysaccharides: Bioactivity and Biotechnology (pp. 161-184). Switzerland: Springer International Publishing.

Ozimek, L. K., Kralj, S., van der Maarel, M. J., \& Dijkhuizen, L. (2006). The levansucrase and inulosucrase enzymes of Lactobacillus reuteri 121 catalyse processive and non-processive transglycosylation reactions. Microbiology, 152, 1187-1196.

Paul, S., Bag, S. K., Das, S., Harvill, E. T., \& Dutta, C. (2008). Molecular signature of hypersaline adaptation: Insights from genome and proteome composition of halophilic prokaryotes. Genome Biology, 9(4), R70.

Peña-Cardeña, A., Rodríguez-Alegría, M. E., Olvera, C., \& Munguía, A. L. (2015). Synthesis of fructooligosaccharides by IsIA4, a truncated inulosucrase from Leuconostoc citreum. BMC Biotechnology, 15(1), 2.

Pereira, Y., Petit-Glatron, M. F., \& Chambert, R. (2001). yveB, encoding endolevanase LevB, is part of the sacB-yveB-yveA levansucrase tricistronic operon in Bacillus subtilis. Microbiology, 147(12), 3413-3419.

Peshev, D., \& Van den Ende, W. (2014). Fructans: Prebiotics and immunomodulators. Journal of Functional Foods, 8, 348-357.

Peshev, D., Vergauwen, R., Moglia, A., Hideg, E., \& Van den Ende, W. (2013). Towards understanding vacuolar antioxidant mechanisms: A role for fructans? Journal of Experimental Botany, 64(4), 1025-1038.

Peukert, M., Thiel, J., Peshev, D., Weschke, W., Van den Ende, W., Mock, H. P., \& Matros, A. (2014). Spatio-temporal dynamics of fructan metabolism in developing barley grains. Plant Cell, 26(9), 3728-3744.

Phelps, C. F. (1965). The physical properties of inulin solutions. Biochemical Journal, 95, 41-47.

Pilon-Smits, E. A. H., Ebskamp, M. J. M., Jeuken, M. J. W., van der Meer, I. M., Visser, R. G. F., Weisbeek, P. J., \& Smeekens, S. C. M. (1996). Microbial fructan production in transgenic potato plants and tubers. Industrial Crop Production, 5, 35-46.

Pilon-Smits, E. A. H., Ebskamp, M. J. M., Paul, M. J., Jeuken, M. J. W., Weisbeek, P. J., \& Smeekens, S. C. M. (1995). Improved performance of transgenic fructan-accumulating tobacco under drought stress. Plant Physiology, 107, 125-130.

Pilon-Smits, E. A. H., Terry, N., Sears, T., \& van Dun, K. (1999). Enhanced drought resistance in fructan-producing sugar beet. Plant Physiology and Biochemistry, 37, 313-317.

Piotrowicz-Cieslak, A. I., Gielwanowska, I., Bochenek, A., Loro, P., \& Górecki, R. J. (2005). Carbohydrates in Colobanthus quitensis and Deschampsia antarctica. Acta Societatis Botanicorum Poloniae, 74(3), 209-217.

Poli, A., Kazak, H., Gürleyendağ, B., Tommonaro, G., Pieretti, G., Öner, E. T., \& Nicolaus, B. (2009). High level synthesis of levan by a novel
Halomonas species growing on defined media. Carbohydrate Polymers, 78(4), 651-657.

Poli, A., Nicolaus, B., Denizci, A. A., Yavuzturk, B., \& Kazan, D. (2013). Halomonas smyrnensis sp. nov., a moderately halophilic, exopolysaccharide-producing bacterium. International Journal of Systematic and Evolutionary Microbiology, 63(1), 10-18.

Pollock, T. J. (1993). Gellan-related polysaccharides and the genus Sphingomonas. Microbiology, 139(8), 1939-1945.

Porras-Domínguez, J. R., Ávila-Fernández, Á., Rodríguez-Alegría, M. E., Miranda-Molina, A., Escalante, A., González-Cervantes, R., ... Munguía, A. L. (2014). Levan-type FOS production using a Bacillus licheniformis endolevanase. Process Biochemistry, 49(5), 783-790.

Puchta, H. (2017). Applying CRISPR/Cas for genome engineering in plants: The best is yet to come. Current Opinion in Plant Biology, 36, 1-8.

Puebla, A. F., Salerno, G. L., \& Pontis, H. G. (1997). Fructan metabolism in two species of Bromus subjected to chilling and water stress. New Phytologist, 136(1), 123-129.

Rafigh, S. M., Yazdi, A. V., Vossoughi, M., Safekordi, A. A., \& Ardjmand, M. (2014). Optimization of culture medium and modeling of curdlan production from Paenibacillus polymyxa by RSM and ANN. International Journal of Biological Macromolecules, 70, 463-473.

Rainey, F. A., Whitman, W. B., Krieg, N. R., Garrity, G. M., Vos, P., Schleifer, K. H., ... Ludwig, W. (2009). Bergey's manual ${ }^{\circledR}$ of systematic bacteriology: Volume three the Firmicutes. New York: Springer.

Ranwala, A. P., \& Miller, W. B. (2008). Analysis of nonstructural carbohydrates in storage of organs of 30 ornamental geophytes by highperformance anion-exchange chromatography with pulsed amperometric detection. New Phytologist, 180, 421-433.

Rao, R. S. P., Andersen, J. R., Dionisio, G., \& Boelt, B. (2011). Fructan accumulation and transcription of candidate genes during cold acclimation in three varieties of Poa pratensis. Journal of Plant Physiology, 168(4), 344-351.

Ratter, J. A., Ribeiro, J. F., \& Bridgewater, S. (1997). The Brazilian Cerrado vegetation and threats to its biodiversity. Annals of Botany, 80(3), 223-230.

Reed, C. J., Bushnell, S., \& Evilia, C. (2014). Circular dichroism and fluorescence spectroscopy of cysteinyl-tRNA synthetase from Halobacterium salinarum ssp. NRC-1 demonstrates that group I cations are particularly effective in providing structure and stability to this halophilic protein. PLoS One, 9(3). e89452

Ripley, B., Frole, K., \& Gilbert, M. (2010). Differences in drought sensitivities and photosynthetic limitations between co-occurring C3 and C4 (NADP-ME) Panicoid grasses. Annals of Botany, 105, 493-503.

Ritsema, T., Hernández, L., Verhaar, A., Altenbach, D., Boller, T., Wiemken, A., \& Smeekens, J. (2006). Developing fructan-synthesizing capability in a plant invertase via mutations in the sucrose-binding box. The Plant Journal, 48, 228-237.

Ritsema, T., \& Smeekens, S. C. M. (2003). Engineering fructan metabolism in plants. Journal of Plant Physiology, 160, 811-820.

Ritsema, T., Verhaar, A., Vijn, I., \& Smeekens, J. (2004). Fructosyltransferase mutants specify a function for the $\beta$-fructosidase motif of the sucrosebinding box in specifying the fructan type synthesized. Plant Molecular Biology, 54, 853-863.

Roach, D. R., Sjaarda, D. R., Castle, A. J., \& Svircev, A. M. (2013). Host exopolysaccharide quantity and composition impact Erwinia amylovora bacteriophage pathogenesis. Applied and Environmental Microbiology, 79(10), 3249-3256.

Robe, W. E., \& Griffiths, H. (2000). Physiological and photosynthetic plasticity in the amphibious, freshwater plant, Littorella uniflora, during the transition from aquatic to dry terrestrial environments. Plant, Cell \& Environment, 23, 1041-1054.

Roberfroid, M. (2005). Inulin-type fructans: Functional food ingredients. Boca Raton, Florida: CRC Press.

Rosell, K. G., \& Birkhed, D. (1974). An inulin-like fructan produced by Streptococcus mutans strain JC2. Acta Chemica Scandinavica, B28, 589. 
Sah, S. K., Reddy, K. R., \& Li, J. (2016). Abscisic acid and abiotic stress tolerance in crop plants. Frontiers in Plant Science, 7, 571.

Salinas, C., Handford, M., Pauly, M., Dupree, P., \& Cardemil, L. (2016). Structural modifications of fructans in Aloe barbadensis Miller (Aloe vera) grown under water stress. PLoS One, 11(7). e0159819

Sandrin, C. Z., Figueiredo-Ribeiro, R. D. C. L., Delitti, W. B. C., \& Domingos, M. (2013). Short-term changes of fructans in ryegrass (Lolium multiflorum "Lema") in response to urban air pollutants and meteorological conditions. Ecotoxicology and Environmental Safety, 96, 80-85.

Santos-Moriano, P., Fernandez-Arrojo, L., Poveda, A., Jimenez-Barbero, J., Ballesteros, A. O., \& Plou, F. J. (2015). Levan versus fructooligosaccharide synthesis using the levansucrase from Zymomonas mobilis: Effect of reaction conditions. Journal of Molecular Catalysis B: Enzymatic, 119, 18-25.

Sawada, D., Ogawa, T., Miyake, M., Hasui, Y., Yamaguchi, F., Izumori, K., \& Tokuda, M. (2015). Potent inhibitory effects of D-tagatose on the acid production and water-insoluble glucan synthesis of Streptococcus mutans GS5 in the presence of sucrose. Acta Medica Okayama, 69(2), 105-111.

Schmid, J., Meyer, V., \& Sieber, V. (2011). Scleroglucan: Biosynthesis, production and application of a versatile hydrocolloid. Applied Microbiology and Biotechnology, 91(4), 937-947.

Schmid, J., Sieber, V., \& Rehm, B. (2015). Bacterial exopolysaccharides: Biosynthesis pathways and engineering strategies. Frontiers in Microbiology, 6, 496 .

Schroeven, L., Lammens, W., Van Laere, A., \& Van den Ende, W. (2008). Transforming wheat vacuolar invertase into a high affinity sucrose: sucrose 1-fructosyltransferase. New Phytologist, 180, 822-831.

Seki, M., Ohara, T., Hearn, T. J., Frank, A., da Silva, V. C. H., Caldana, C., ... Satake, A. (2017). Adjustment of the Arabidopsis circadian oscillator by sugar signaling dictates the regulation of starch metabolism. Scientific Reports, 7, 8305.

Sengupta, S., Mukherjee, S., Basak, P., \& Majumder, A. L. (2015). Significance of galactinol and raffinose family oligosaccharide synthesis in plants. Frontiers in Plant Science, 6, 656.

Shane, M. W., \& Pate, J. S. (2015). Survival strategies of the root tuberous geophyte Chamaescilla corymbosa in a Mediterranean-climate rock-outcrop environment. Australian Journal of Botany, 63(6), 497-511.

Simpson, M. G. (2010). Chapter 8: Diversity and classification of Flowering Plants: Eudicots. In M. G. Simpson (Ed.), Plant Systematics (2nd ed.) (pp. 275-448). Singapore: Academic Press.

Sims, I. M. (2003). Structural diversity of fructans from members of the order Asparagales in New Zealand. Phytochemistry, 63, 351-359.

Sørensen, S. J., Bailey, M., Hansen, L. H., Kroer, N., \& Wuertz, S. (2005). Studying plasmid horizontal transfer in situ: A critical review. Nature Reviews Microbiology, 3(9), 700-710.

Souza, C. A., Li, S., Lin, A. Z., Boutrot, F., Grossmann, G., Zipfel, C., \& Somerville, S. C. (2017). Cellulose-derived oligomers act as damageassociated molecular patterns and trigger defense-like responses. Plant Physiology, 173, 2383-2398.

Suárez-González, E. M., López, M. G., Délano-Frier, J. P., \& Gómez-Leyva, J. F. (2014). Expression of the 1-SST and 1-FFT genes and consequent fructan accumulation in Agave tequilana and $A$. inaequidens is differentially induced by diverse (a)biotic-stress related elicitors. Journal of Plant Physiology, 171(3), 359-372.

Sulpice, R., Flis, A., Ivakov, A. A., Apelt, F., Krohn, N., Encke, B., ... Stitt, M. (2014). Arabidopsis coordinates the diurnal regulation of carbon allocation and growth across a wide range of photoperiods. Molecular Plant, 7 , 137-155.

Sutherland, I. W. (1972). Bacterial exopolysaccharides. Advances in Microbial Physiology, 8, 143-213.

Takahashi, D., Li, B., Nakayama, T., Kawamura, Y., \& Uemura, M. (2013). Plant plasma membrane proteomics for improving cold tolerance. Frontiers in Plant Science, 4, 90
Tamaru, Y., Takani, Y., Yoshida, T., \& Sakamoto, T. (2005). Crucial role of extracellular polysaccharides in desiccation and freezing tolerance in the terrestrial cyanobacterium Nostoc commune. Applied and Environmental Microbiology, 71(11), 7327-7333.

Tamura, K. I., Sanada, Y., Tase, K., Kawakami, A., Yoshida, M., \& Yamada, T. (2014). Comparative study of transgenic Brachypodium distachyon expressing sucrose:fructan 6-fructosyltransferases from wheat and timothy grass with different enzymatic properties. Planta, 239(4), 783-792.

Tapia, H., \& Koshland, D. E. (2014). Trehalose is a versatile and long-lived chaperone for desiccation tolerance. Current Biology, 24, 2758-2766.

Tarkowski, Ł. P., \& Van den Ende, W. (2015). Cold tolerance triggered by soluble sugars: A multifaceted countermeasure. Frontiers in Plant Science, 6, 203.

Tertuliano, M. F., \& Figueiredo-Ribeiro, R. C. L. (1993). Distribution of fructose polymers in herbaceous species of Asteraceae from the Cerrado. New Phytologist, 123(4), 741-749.

Thorsteinsson, B., Harrison, P. A., \& Chatterton, N. J. (2002). Fructan and total carbohydrate accumulation in leaves of two cultivars of timothy (Phleum pretense Vega and Climax) as affected by temperature. Journal of Plant Physiology, 159(9), 999-1003.

Toksoy Öner, E., Hernández, J., \& Combie, J. (2016). Review of levan polysaccharide: From a century of past experiences to future prospects. Biotechnology Advances, 34, 827-844.

Tolsma, A. D., Read, S. M., \& Tolhurst, K. G. (2007). Roots of Australian alpine plant species contain high levels of stored carbohydrates independent of post-fire regeneration strategy. Australian Journal of Botany, 55(8), 771-779.

Tolsma, A. D., Tolhurst, K. G., \& Read, S. M. (2010). Effects of fire, post-fire defoliation, drought and season on regrowth and carbohydrate reserves of alpine snowgrass Poa fawcettiae (Poaceae). Australian Journal of Botany, 58(3), 157-168.

Trollope, K. M., Wyk, N., Kotjomela, M. A., \& Volschenk, H. (2015). Sequence and structure-based prediction of fructosyltransferase activity for functional subclassification of fungal GH32 enzymes. The FEBS Journal, 282(24), 4782-4796.

Trouvelot, S., Héloir, M. C., Poinssot, B., Gauthier, A., Paris, F., Guillier, C., ... Adrian, M. (2014). Carbohydrates in plant immunity and plant protection: Roles and potential application as foliar sprays. Frontiers in Plant Science, 5, 592.

Valluru, R., Lammens, W., Claupein, W., \& Van den Ende, W. (2008). Freezing tolerance by vesicle-mediated fructan transport. Trends in Plant Science, 13(8), 409-414.

Valluru, R., \& Van den Ende, W. (2008). Plant fructans in stress environments: Emerging concepts and future prospects. Journal of Experimental Botany, 59(11), 2905-2916.

van Arkel, J., Sévenier, R., Hakkert, J. C., Bouwmeester, H. J., Koops, A. J., \& van der Meer, I. M. (2013). Tailor-made fructan synthesis in plants: A review. Carbohydrate Polymers, 93, 48-56.

Van den Ende, W. (2013). Multifunctional fructans and raffinose family oligosaccharides. Frontiers in Plant Science, 4, 247.

Van den Ende, W., Clerens, S., Vergauwen, R., Boogaerts, D., Le Roy, K., Arckens, L., \& Van Laere, A. (2006). Cloning and functional analysis of a high DP fructan: fructan 1-fructosyl transferase from Echinops ritro (Asteraceae): Comparison of the native and recombinant enzymes. Journal of Experimental Botany, 57(4), 775-789.

Van den Ende, W., Coopman, M., Clerens, S., Vergauwen, R., Le Roy, K., Lammens, W., \& Van Laere, A. (2011). Unexpected presence of graminan-and levan-type fructans in the evergreen frost-hardy eudicot Pachysandra terminalis (Buxaceae): Purification, cloning, and functional analysis of a 6-SST/6-SFT enzyme. Plant Physiology, 155(1), 603-614.

Van den Ende, W., Coopman, M., Vergauwen, R., \& Van Laere, A. (2016). Presence of inulin-type fructo-oligosaccharides and shift from raffinose family oligosaccharide to fructan metabolism in leaves of boxtree (Buxus sempervirens). Frontiers in Plant Science, 7, 209. 
Van den Ende, W., De Coninck, B., \& Van Laere, A. (2004). Plant fructan exohydrolases: A role in signaling and defense? Trends in Plant Science, 9(11), 523-528.

Van den Ende, W., De Coninck, B., Clerens, S., Vergauwen, R., \& Van Laere, A. (2003). Unexpected presence of fructan 6-exohydrolases (6-FEHs) in non-fructan plants: Characterization, cloning, mass mapping and functional analysis of a novel "cell-wall invertase-like" specific 6-FEH from sugar beet (Beta vulgaris L.). The Plant Journal, 36(5), 697-710.

Van den Ende, W., Van Laere, A., Le Roy, K., Vergauwen, R., Boogaerts, D., Figueiredo-Ribeiro, R. C., \& Machado de Carvalho, M. A. (2005). Molecular cloning and characterization of a high DP fructan: fructan 1-fructosyl transferase from Viguiera discolor (Asteraceae) and its heterologous expression in Pichia pastoris. Physiologia Plantarum, 125(4), 419-429.

Van den Ende, W., \& Van Laere, A. (1996). Fructan synthesizing and degrading activities in chicory roots (Cichorium intybus L.) during fieldgrowth, storage and forcing. Journal of Plant Physiology, 149, 43-50.

Van der Nest, M. A., Steenkamp, E. T., McTaggart, A. R., Trollip, C., Godlonton, T., Sauerman, E., ... Wingfield, M. J. (2015). Saprophytic and pathogenic fungi in the Ceratocystidaceae differ in their ability to metabolize plant-derived sucrose. BMC Evolutionary Biology, 15(1), 273.

Van Laere, A., \& Van den Ende, W. (2002). Inulin metabolism in dicots: Chicory as a model system. Plant, Cell \& Environment, 25(6), 803-813.

Vasiliu, S., Racovita, S., Lungan, M. A., Desbrieres, J., \& Popa, M. (2016). Microbial exopolysaccharides for biomedical applications. Frontiers in Biomaterials: Unfolding the Biopolymer Landscape, 2, 180.

Velázquez-Hernández, M. L., Baizabal-Aguirre, V. M., Bravo-Patiño, A., Cajero-Juárez, M., Chávez-Moctezuma, M. P., \& Valdez-Alarcón, J. J. (2009). Microbial fructosyltransferases and the role of fructans. Journal of Applied Microbiology, 106(6), 1763-1778.

Verhaest, M., Van den Ende, W., Le Roy, K., De Ranter, C. J., Van Laere, A., \& Rabijns, A. (2004). X-ray diffraction structure of a plant glycosyl hydrolase family 32 protein: Fructan 1-exohydrolase Ila of Cichorium intybus. The Plant Journal, 41, 400-411.

Versluys, M., Tarkowski, Ł. P., \& Van den Ende, W. (2017). Fructans as DAMPs or MAMPs: Evolutionary prospects, cross-tolerance, and multistress resistance potential. Frontiers in Plant Science, 7, 2061.

Verspreet, J., Dornez, E., Van den Ende, W., Delcour, J. A., \& Courtin, C. M. (2015). Cereal grain fructans: Structure, variability and potential health effects. Trends in Food Science \& Technology, 43(1), 32-42.

Verspreet, J., Hansen, A., Harrison, S., Vergauwen, R., Van den Ende, W., \& Courtin, C. (2017). Building a fructan LC-MS2 library and its application to reveal the fine structure of cereal grain fructans. Carbohydrate Polymers, 174, 343-351.

Vijn, I., \& Smeekens, S. (1999). Fructan: More than a reserve carbohydrate? Plant Physiology, 120(2), 351-360.

Vinnersten, A., \& Bremer, K. (2001). Age and biogeography of major clades in Liliales. American Journal of Botany, 88(9), 1695-1703.

Vogt, L., Ramasamy, U., Meyer, D., Pullens, G., Venema, K., Faas, M. M., ... de Vos, P. (2013). Immune modulation by different types of $\beta 2 \rightarrow 1$ fructans is Toll-like receptor dependent. PLoS One, 8. e68367
Volaire, F., Thomas, H., \& Lelievre, F. (1998). Survival and recovery of perennial forage grasses under prolonged Mediterranean drought: I. Growth, death, water relations and solute content in herbage and stubble. New Phytologist, 140(3), 439-449.

Wahyuningrum, D., \& Hertadi, R. (2015). Isolation and characterization of levan from moderate halophilic bacteria Bacillus licheniformis BK AG21. Procedia Chemistry, 16, 292-298.

Wang, C., Hua, D., \& Yan, C. (2015). Structural characterization and antioxidant activities of a novel fructan from Achyranthes bidentata Blume, a famous medicinal plant in China. Industrial Crops and Products, 70, 427-434.

Wang, N., \& Nobel, P. S. (1998). Phloem transport of fructans in the crassulacean acid metabolism species Agave deserti. Plant Physiology, 116(2), 709-714.

Wang, W., Barnaby, J. Y., Tada, Y., Li, H., Tor, M., Caldelari, D., ... Dong, $X . N$. (2011). Timing of plant immune responses by a central circadian regulator. Nature, 470, 110-126.

Wei, H., Bausewein, A., Steininger, H., Su, T., Zhao, H., Harms, K., ... Rausch, T. (2016). Linking expression of fructan active enzymes, cell wall invertases and sucrose transporters with fructan profiles in growing taproot of chicory (Cichorium intybus): Impact of hormonal and environmental cues. Frontiers in Plant Science, 7, 1806.

Wellman, C. H., Osterloff, P. L., \& Mohiuddin, U. (2003). Fragments of the earliest land plants. Nature, 425, 282-285.

Yanase, H., Maeda, M., Hagiwara, E., Yagi, H., Taniguchi, K., \& Okamoto, K. (2002). Identification of functionally important amino acid residues in Zymomonas mobilis levansucrase. Journal of Biochemistry, 132(4), 565-572.

Yoshida, M., Abe, J., Moriyama, M., \& Kuwabara, T. (1998). Carbohydrate levels among winter wheat cultivars varying in freezing tolerance and snow mold resistance during autumn and winter. Physiologia Plantarum, 103(1), 8-16.

Zhang, G., \& Yi, L. (2013). Stability of halophilic proteins: From dipeptide attributes to discrimination classifier. International Journal of Biological Macromolecules, 53, 1-6.

Zhang, Q., Song, X., \& Bartels, D. (2016). Enzymes and metabolites in carbohydrate metabolism of desiccation tolerant plants. Proteomes, 4, 40.

Zwicke, M., Picon-Cochard, C., Morvan-Bertrand, A., Prud'homme, M. P., \& Volaire, F. (2015). What functional strategies drive drought survival and recovery of perennial species from upland grassland? Annals of Botany, 116(6), 1001-1015.

How to cite this article: Versluys M, Kirtel O, Toksoy Öner E, Van den Ende W. The fructan syndrome: Evolutionary aspects and common themes among plants and microbes. Plant Cell Environ. 2018;41:16-38. https://doi.org/10.1111/pce.13070 